\title{
Effect of the choice of different methods on the permeable pavement hydraulic characterization and hydrological classification
}

\author{
Larissa Virgínia da Silva Ribas ${ }^{1}$, Artur Paiva Coutinho ${ }^{2}$, Laurent Lassabatere ${ }^{3 *}$, Severino Martins dos \\ Santos Neto ${ }^{2}$, Suzana Maria Gico Lima Montenegro ${ }^{4}$, Ana Emília Carvalho de Gusmão da Cunha Rabeloº \\ Rafael Angulo Jaramillo ${ }^{3}$, Alfredo Ribeiro Neto ${ }^{4}$ \\ ${ }^{1}$ Department of Transport Engineering and Geodesy, Federal University of Bahia, BA, Brazil. \\ 2 Agreste Academic Center, 2 - Federal University of Pernambuco, PE, Brazil. \\ ${ }^{3}$ Univ Lyon, Université Claude Bernard Lyon 1, CNRS, ENTPE, UMR5023 LEHNA, F-69518, Vaulx-en-Velin, France. \\ ${ }^{4}$ Department of Civil and Environmental Engineering, Federal University of Pernambuco, Recife, Brazil. \\ * Corresponding author. E-mail: laurent.lassabatere@entpe.fr
}

\begin{abstract}
The permeable pavement is a compensatory drainage technique for urban waters that aims to control runoff and to ensure ideal hydrological conditions. This work had as main objectives to evaluate the infiltration capacity of a permeable pavement (PP) at real scale, through analytical and numerical modeling. It relies on water infiltration experiments and related modeling for the hydrodynamic characterization of the coating layer (saturated hydraulic conductivity, $K_{s}$, and sorptivity, $S$ ). A large panel of analytical and numerical models was considered, and several estimates were obtained. Then, the criteria for the evaluation of the maintenance requirement of the permeable pavements were computed for all the $K_{s}$-estimates considering the NCRS standards (assessment of permeability levels). The results indicated nice fits and accurate estimates for both the saturated hydraulic conductivity and the sorptivity. However, the $K_{s}$-estimates depended on the considered model and led to contrasting results in terms of classification. For 8 of the 9 models, the value of the $K_{s}$-estimate leads to the classification of "Group A" of the NCRS soil classification, meaning a very permeable material. In contrasts, the last method (numerical inverse modeling) classified the permeable pavement as "Group D", i.e., soils with low permeability. Those results show the importance of the selection of characterization methods regarding the assessment of the hydrological classification of permeable pavements.
\end{abstract}

Keywords: Water infiltration techniques; Hydraulic conductivity; Compensatory techniques; Analytical methods; Numerical inversion; Hydrodynamic indicators.

\section{INTRODUCTION}

Affected by practically every stage of its process, the hydrological cycle components in urban areas undergo continuous changes. Due to the increase in waterproofed areas, the infiltration is severely reduced, and much of the precipitation generates surface runoff water (Fletcher et al., 2013). By reducing the concentration-time of these urban basins, high flow peaks combined with the undersized drainage system and/or the lack of maintenance and related clogging, cause recurrent and dangerous flood events. Besides the numerous social and economic damages, urban floods are also a problem of public and environmental health. Indeed, runoff water carries significant pollutant loads thus contaminating groundwater bodies, fauna, flora, and in turns humans (Xie et al., 2019; Zhu et al., 2019).

The urban drainage compensatory techniques aim to quantitatively and qualitatively control runoff (Fletcher et al., 2015). For this purpose, a systemic and multidisciplinary approach is often conducted by municipalities to permeabilize urban areas to restore hydrological conditions as close as possible to those prior urbanization. These may consist of construction works, structures, and devices that facilitate the infiltration and percolation of water in the soil, restricting the runoff water infiltration into the drainage network, or that temporarily store runoff water. Among the most commonly known compensatory techniques used in Brazil, we find the infiltration systems, the infiltration wells and trenches, the detention basins, the green roofs, and the permeable pavements (Canholi, 2015; Costa et al., 2020; Marinho et al., 2020).

The permeable pavement is a compensatory technique, which consists of an infiltration surface composed of a porous coating and a subsurface reservoir for the storage of water, encompassing a large panel of designs (Mullaney and Lucke, 2014). The hydraulic performance of the pavement is associated with the type of material used, its hydrodynamic properties and the maintenance periodicity of the system. The need to maintain the porous pavement performance is crucial with regards to the preservation of the hydrological conditions of peri-urbanized areas, with the appropriate promotion of drainage and rainwater systems (Chandrappa and Biligiri, 2016). The hydraulic performance of permeable pavements has been the subject of several investigations (AlShareedah and Nassiri, 2021). Permeable pavements ensure water infiltration into the voids between concrete blocks and into the concrete blocks when these are porous and permeable (e.g., Brunetti et al., 2016; Turco et al., 2017). For concrete grid pavements, for which the large voids between concrete blocks are filled in with soil, the soil quality and its hydraulic properties are crucial with regards to the bulk efficiency of the pavement to infiltrate (Boogaard et al., 2014). The prediction of water infiltration and hydraulic response of the PP requires, in this case, the determination of the soil hydraulic properties.

The estimation of the hydrodynamic properties of the soil of the concrete grid pavements can be performed by infiltration tests. Indeed, several types of infiltration tests and mathematical 
methods may be used for the hydraulic characterization of porous media, including the determination of the unsaturated hydraulic conductivity and the water retention curves (AnguloJaramillo et al., 2016). However, an accurate estimation of these may be fundamental for assessing infiltration capacity of the permeable pavements. Indeed, the analysis of the timeevolution of hydraulic characteristics may make it possible to identify the potential decrease in infiltration performance over time and point at pore sealing and clogging. Lastly, the hydraulic characteristics are needed for the numerical modelling of the hydraulic responses of these infiltration systems, and in particular for the quantification of the runoff and soil water infiltrations depending on situations and scenarios in terms of rainfall events and dry periods. A proper estimation of hydrodynamic properties is then a prerequisite for the assessment of the performance of concrete grid pavements and their benefits in urban environments, as well as the need for maintenance interventions for the optimized operation of these systems (Huang et al., 2016).

If infiltration techniques are quite common, several mathematical methods may be used for the treatment of the same experimental data and the derivation of the hydraulic properties. The estimates provided by the different mathematical treatments may result in contrasting results and then contrasting assessments of the infiltration capacity of the same soils and permeable pavements. A choice must be assumed regarding the most appropriate estimates of the hydraulic functions. In a previous work, Coutinho et al. (2016) performed several water infiltration tests and used BEST methods (Lassabatere et al., 2013) for the determination of the infiltration capacity of a permeable pavement of the type concrete grid pavement in an urban area of Recife (Pernambuco, Brazil) (Coutinho et al., 2016). The proposed study is complementary to that of Coutinho et al. (2016). This study treats the same experimental data with several methods to derive the saturated hydraulic conductivity and related indicators for infiltration capability.
The studied methods are among the most famous and often used to determine saturated hydraulic conductivity and sorptivity: Wu 1 and Wu 2 methods (Wu et al., 1999), the Steady Simplified Beerkan infiltration SSBI method (Bagarello et al., 2017, 2014b), five models one-dimensional infiltration (Brutsaert, 1977; Philip, 1957; Philip and Knight, 1974; Stroosnijder, 1976; Swartzendruber, 1987), and finally inverse modelling based on the resolution of Richards' equation. Once the hydraulic parameters are estimated, these are used to compute criteria related to hydrological classifications systems for the evaluation of infiltration capability. This analysis points out some limitations of the hydrological classification systems derived from water infiltration experiments: criteria are strongly dependent on the methods used for the prediction of hydraulic conductivity, and thus potential variable.

\section{MATERIAL AND METHODS}

\subsection{Experimental site and water infiltration experiments}

The studied pilot permeable pavement is located in the parking lot of the Center of Technology and Geosciences (CTG) of the Federal University of Pernambuco - UFPE, in the neighborhood of Cidade Universitária - Recife / PE, at the geographic coordinates $8^{\circ} 03^{\prime} 67^{\prime \prime}$ and $34^{\circ} 57^{\prime} 12^{\prime \prime}$ (Fig. 1). The pilot pavement was built in 2010 for academic purposes. It was designed to drain a parking lot area of $110 \mathrm{~m}^{2}$, occupying a rectangular area of $4.5 \mathrm{~m}^{2}$ and having a total thickness of $64 \mathrm{~cm}$. Previous studies involving the hydraulic and hydrological characterization of the permeable pavement system have already been carried out in this experimental area (Coutinho et al., 2016), with just the one of one way to treat data.

The PP coating belongs to the family of concrete grid pavers - CGP (Mullaney and Lucke, 2014). The PP is composed of concrete blocks of which void spaces were filled with soil and grass, set on a draining mattress (Fig. 2). In order to provide better interlocking of the units, the grout used between

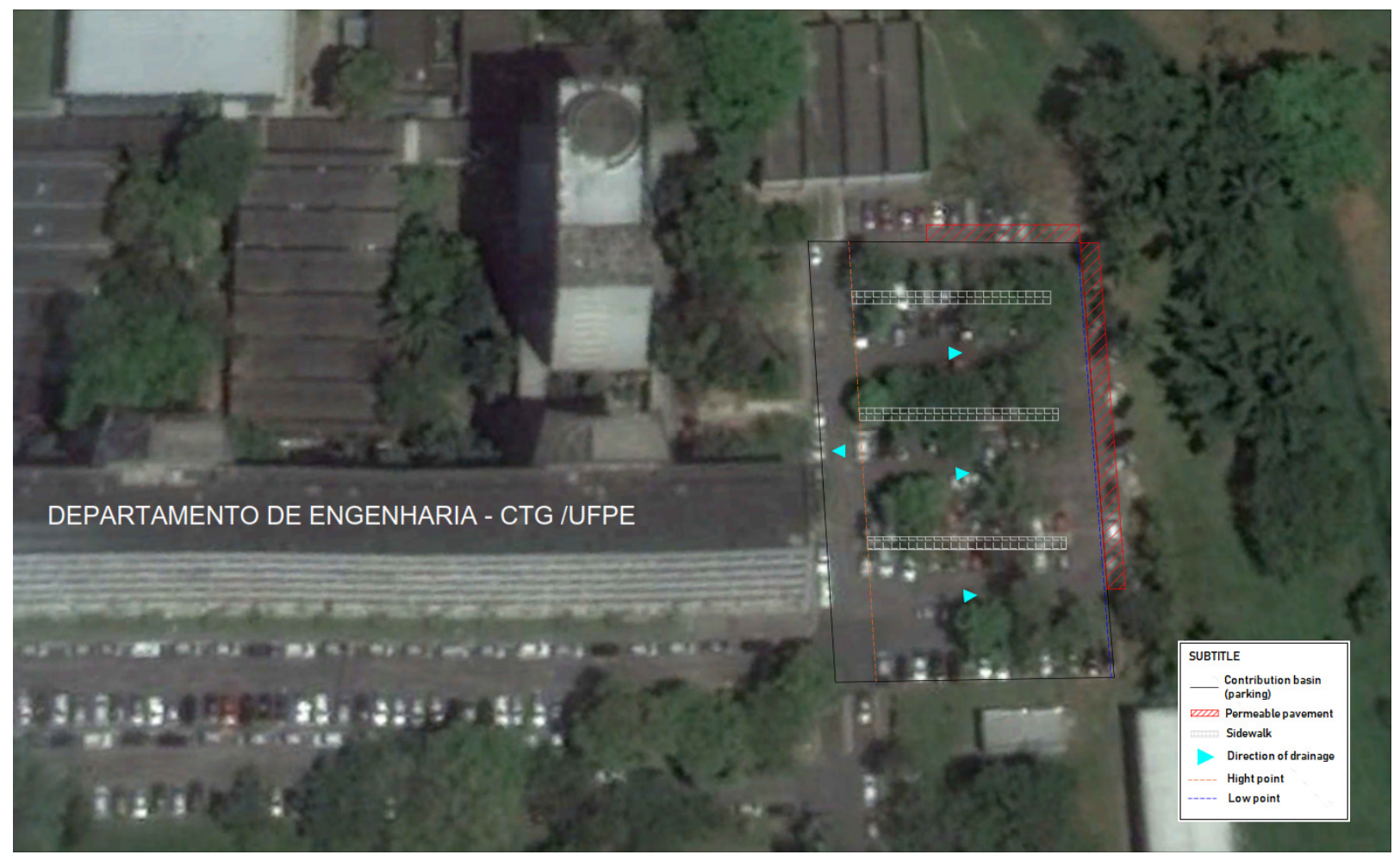

Fig. 1. Location/situation map of the PP - CTG Parking Lot- UFPE, delimitation of the contribution basins and directions of the flows. 


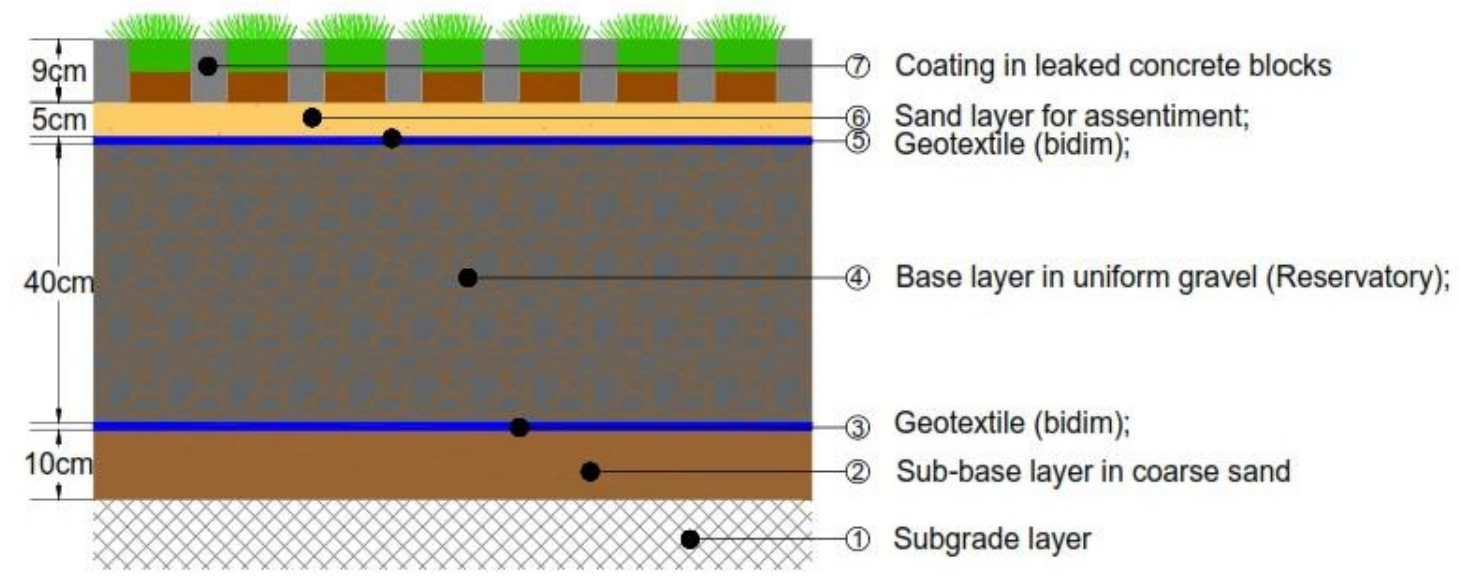

Fig. 2. Structure of the permeable pavement.

the blocks was conventional mortar. The subbase layer, $40 \mathrm{~cm}$ in thickness, consists of granular material, gravel of uniform granulometry with a porosity of $43 \%$, which function is to serve as reservoir (water storage) (Fig. 2). Below, a sub-base layer made of coarse sand spans over $10 \mathrm{~cm}$ depth. Then, a final layer (subgrade layer) separates the structures from the native soil. Geotextiles were used to separate materials with contrasting particle sizes to avoid soil particle transfer between materials (Fig. 2). Coutinho et al. (2016) considered that for this structure, the global infiltration capacity of the system is limited by the infiltration capacity of the soil below the structure. This means that for all precipitation events, the storage capacity of the subbase and its hydraulic conductivity need to be sufficient to ensure complete storage of the infiltrated water. The structure of the permeable pavement is described in more details in Fig. 2.

During its construction, the pilot was equipped with observation wells, instruments to monitor the soil moisture, and capsule tensiometers to monitor the soil matric potential. However, the monitoring of these hydraulic variables is beyond the scope of this paper.

To characterize the hydraulic and hydrological behavior of the permeable pavement, Coutinho et al. (2016) carried out infiltration tests and collected soil samples in the PP according to a rectangular mesh of $1.0 \mathrm{~m} \times 0.7 \mathrm{~m}$, gathering 52 points. The infiltration tests were performed according to the Beerkan methodology (Braud et al., 2005; Lassabatere et al., 2006), using a $75 \mathrm{~mm}$ diameter simple ring infiltrometer. The volumes of water used in the experiments were set at $50 \mathrm{~cm}^{3}$. For each point, the tests continued until steady state, and the initial moisture condition, final moisture content, particle size distribution and soil specific mass were also determined. These data allow the determination of the saturated hydraulic conductivity for each point. In this study, we used the same data but treated it with additional modeling approaches.

\subsection{Determination of saturated hydraulic conductivity $K_{s}$ and sorptivity $S$}

The campaign of water infiltration experiments was already carried out (Coutinho et al., 2016) and the related data treated using the BEST methods including BEST Slope (Lassabatere et al., 2006), BEST Intercept (Yilmaz et al., 2010), and BEST Steady (Bagarello et al., 2014a). In this study, we extended the treatment of the same data using a large panel of modeling approaches used for the treatment of water infiltration data. These models issued from the technical and scientific literature are validated regarding their applicability and the conditions of use. The models are compared in terms of the quality of fits to the experimental data and estimates of the hydraulic conductivity and related assessment of infiltration capacity of the pavement.

\section{Steady-state analytical modeling}

The method Wu 2 (Wu et al., 1999) is based on the assumption that the last part of the infiltration curve properly describes the steady state of a 3D infiltration phenomenon (typical result from water infiltration experiments). The experimental data is fitted to the following linear equation and $K_{s}$ can be calculated from:

$I=i \cdot t+c=a f \cdot K_{s} \cdot t+c$

$K_{s}=\frac{i}{a f}$

where $I[\mathrm{~L}]$ is the infiltration data, also referred to as cumulative infiltration, $i[\mathrm{~L} / \mathrm{T}]$ is the slope, $c[\mathrm{~L}]$ is the intercept of the linear regression line, $a$ is dimensionless constants $(a=$ 0.9084 ), and $f$, dimensionless, can be estimated as follows:

$f=\frac{H+\frac{1}{\alpha^{*}}}{G^{*}}+1$

where, $H[\mathrm{~L}]$ is the ponded depth in the ring and $G^{*}=d+r / 2$ $[\mathrm{L}]$, where $d[\mathrm{~L}]$ is the ring insertion depth and $r[\mathrm{~L}]$ is the radius of the ring infiltrometer. The parameter $\alpha^{*}\left[\mathrm{~L}^{-1}\right]$ expressing the relative contribution of capillary forces to infiltration (Reynolds and Elrick, 1990) can be calculated using the Equation 4 (Rawls et al., 1991):

$$
\begin{aligned}
\alpha^{*}= & e\left[5.340+0.185(C)-2.484(\varnothing)-0.002(C)^{2}-\right. \\
& 0.044(S)(\varnothing)-0.6617(C)(\varnothing)+0.001(S)^{2}(\varnothing)^{2}- \\
& 0.009\left(C^{2}\right)\left(\emptyset^{2}\right)-0.00001\left(S^{2}\right)(C)+0.009\left(C^{2}\right)(\varnothing)- \\
& \left.0.0007\left(S^{2}\right)(\varnothing)+0.00000\left(C^{2}\right)(S)+0.500\left(\emptyset^{2}\right) C\right]
\end{aligned}
$$

where $\varnothing\left[\mathrm{L}^{3} / \mathrm{L}^{3}\right]$ is the soil porosity, $\mathrm{C}[\mathrm{M} / \mathrm{M}]$ and $\mathrm{S}[\mathrm{M} / \mathrm{M}]$ are the percentage of clay and sand, respectively.

Another model that explores the steady state of the infiltration event is the Steady Simplified Beerkan Infiltration (SSBI) method developed by Bagarello et al. (2017). The SSBI method fits the experimental data to the same type of equation than Eq. (1) and the saturated hydraulic conductivity, $K_{s}[\mathrm{~L} / \mathrm{T}]$ is computed as follows: 
$K_{s}=\frac{b_{2}}{\frac{\gamma \gamma_{w}}{r \alpha^{*}}+1}$

where $b_{2}[\mathrm{~L} / \mathrm{T}]$ is the slope of the line corresponding to the linear regression of the $(I, t)$ data collected during the steadystate of the infiltration test; $\gamma$ is a shape parameter for geometrical correction of the infiltration bulb, commonly set at 0.75 (Haverkamp et al., 1994); $\gamma_{w}$ is a dimensionless constant related to the shape of the wetting (or drainage) front, fixed set at 1.818 (Reynolds and Elrick, 1990; White and Sully, 1987).

\section{Transient-state analytical modeling}

The 3D infiltration model for the complete solution of the infiltration curve can be described by the two-term equation (Lassabatere et al., 2009) which was used by the Wu 1 method (Wu et al., 1999):

$I=A t+B t^{0.5}$

where $I[\mathrm{~L}]$ is cumulative infiltration, $t[\mathrm{~T}]$ is time, and $A[\mathrm{~L} / \mathrm{T}]$ and $B\left[\mathrm{~L} / \mathrm{T}^{1 / 2}\right]$ are empirical coefficients. This equation was fitted to the $(t, I)$ data pairs measured from the beginning of the single-ring infiltration experiments to obtain an estimate of $A$ and $B . K_{s}$ was then estimated by the following equation:

$K_{s}=\frac{\Delta \theta \cdot\left[\sqrt{\left(H+G^{*}\right)^{2}+4 G^{*} C}-\left(H+G^{*}\right)\right]}{2 T_{c}}$

where $\Delta \theta\left[\mathrm{L}^{3} / \mathrm{L}^{3}\right]$ is the difference between the saturated volumetric soil water content $\left(\theta_{s}\right)$, and the initial volumetric soil water content $\left(\theta_{i}\right) ; H[\mathrm{~L}]$ is the ponded depth in the ring; $G^{*}[\mathrm{~L}]$, $C[\mathrm{~L}]$ and $T_{c}[\mathrm{~T}]$ having the following expressions:

$G^{*}=d+\frac{r}{2}$

$C=\frac{1}{4 \Delta \theta} \cdot\left(\frac{B}{b}\right)^{2} \cdot \frac{a}{A}$

$T_{c}=\frac{1}{4}\left(\frac{B a}{b A}\right)^{2}$ where $d[\mathrm{~L}]$ and $r[\mathrm{~L}]$ are the insert depth of the ring and ring radius, respectively, and $a$ and $b$ are dimensionless constants $(a=0.9084$, and $b=0.1682)$.

\section{One-dimensional infiltration models}

The tests performed on the permeable pavement used the simple ring infiltrometer, leading to $3 \mathrm{D}$ water infiltration. Five classical models developed for 1D water infiltration (Table 1) were adapted to 3D water infiltration by adding the horizontal lateral water flux, as proposed by Smettem et al. (1994):

$I_{3 D}=I_{1 D}+\frac{\gamma \cdot S^{2}}{r \cdot \Delta \theta}$

where $I_{1 D}[\mathrm{~L}]$ corresponds to cumulative infiltration, $\gamma$ is a constant usually considered as $0.75, S\left[\mathrm{~L} / \mathrm{T}^{1 / 2}\right]$ is the soil sorptivity, $r[\mathrm{~L}]$ the ring radius, and $\Delta \theta\left[\mathrm{L}^{3} / \mathrm{L}^{3}\right]$ the difference in water content, as already stated. The parameters $K_{s}, S, \alpha$, and $\beta$, were obtained by fitting experimental data to these models using their versions adapted to $3 \mathrm{D}$ water infiltration. The fitting procedure minimized the following objective function:

$$
F(v)=\sum_{i=1}^{N}\left[I\left(t_{i}\right)-\hat{I}\left(t_{i}, v\right)\right]^{2}
$$

where $I\left(t_{i}\right)$ is the set of values measured at specific times $t_{i}(i=$ $1,2, \ldots \mathrm{N})$, and $\hat{I}\left(t_{i}, v\right)$ is the set of modeled values considering the set of input variables $v=\left\{K_{s}, S, \alpha, \beta\right\}$. Minimization was proceeded using Excel Solver.

\section{Inverse numerical modeling}

Lastly, the hydraulic parameters were derived from the numerical inversion of the experimental data following the procedure developed by Antonino et al. (2004). For that, Hydrus $2 \mathrm{D} / 3 \mathrm{D}$ software was used in this study. Hydrus is often considered for the modeling of water flow and solute transfer in the vadose zone (Šimůnek et al., 2008), and in particular for the inverse modeling of cumulative infiltration curves (Šimůnek and van Genuchten, 1997). Hydrus software resolves the Richards equation for the prediction of flow, allowing the use of several types of water retention and hydraulic conductivity functions and the proper description of initial and boundary conditions.

Table 1. Considered models for 1D cumulative infiltration.

\begin{tabular}{|c|c|c|c|}
\hline 1D infiltration models & Equation & & Parameters \\
\hline Philip (1957) & $I=A \cdot t+S \cdot t^{0.5}+\frac{\gamma \cdot S^{2}}{r \cdot \Delta \theta} t$ & (12) & $\begin{array}{l}K_{S}\left(\mathrm{~mm} \mathrm{~h}^{-1}\right) \\
S\left(\mathrm{~mm} \mathrm{~s}^{-1 / 2}\right)\end{array}$ \\
\hline $\begin{array}{l}\text { The "Knight" soil, } \\
\text { Philip (1974) }\end{array}$ & $I=K_{s} \cdot t+\frac{\pi S^{2}}{4 K_{S}} \cdot\left[1+\left(\frac{4 K_{S}^{2} \cdot t}{\pi S^{2}}\right)^{0.5}\right] t$ & (13) & $\begin{array}{l}K_{s}\left(\mathrm{~mm} \mathrm{~h}^{-1}\right) \\
\left.S\left(\mathrm{~mm} \mathrm{~s}^{-1 / 2}\right)\right)\end{array}$ \\
\hline Stroosnijder (1976) & $I=K_{S} \cdot t+\frac{3 S^{2}}{4 K_{S}} \cdot\left[-\exp \left(\frac{-4 \cdot K_{S} \cdot t^{0.5}}{3 S}\right)\right.$ & (14) & $\begin{array}{l}K_{s}\left(\mathrm{~mm} \mathrm{~h}^{-1}\right) \\
S\left(\mathrm{~mm} \mathrm{~s}^{-1 / 2}\right)\end{array}$ \\
\hline Brutsaert (1977) & $I=K_{s} \cdot t+\frac{S^{2}}{\beta \cdot K_{S}} \cdot\left[1-\frac{1}{1+\beta \cdot \frac{K_{S} \sqrt{t}}{S}}\right]$ & $(15)$ & $\begin{array}{c}K_{s}\left(\mathrm{~mm} \mathrm{~h}^{-1}\right) \\
S\left(\mathrm{~mm} \mathrm{~s}^{-1 / 2}\right) \\
\quad \beta=0.6\end{array}$ \\
\hline Swartzendruber (1987) & $I=K_{s} \cdot t+\frac{S}{\alpha} \cdot\left[1-\exp \left(-\alpha \cdot t^{0.5}\right)\right]$ & (16) & $\begin{array}{c}K_{s}\left(\mathrm{~mm} \mathrm{~h}^{-1}\right) \\
S\left(\mathrm{~mm} \mathrm{~s}^{-1 / 2}\right) \\
\alpha\end{array}$ \\
\hline
\end{tabular}


The cumulative infiltrations are computed assuming homogeneous soils, considering the upper layer. Indeed, when the soil is layered and when the upper layer is the less permeable, water infiltration is more representative of the upper layer (Lassabatere et al., 2010). The numerical domain was considered axisymmetric and was discretized in triangular elements of $5 \mathrm{~cm}$ edge, forming a numerical structure with 5722 nodes, 240 1D elements and 11202 2D elements. Uniform distributions of initial water pressure heads were considered, their values being deduced from the measures of initial water contents, using the water retention curves estimated by Countinho et al. (2016). The boundary conditions were fixed at null pressure head over the ring area, free drainage at the bottom boundary and zero flux elsewhere (Fig. 3), as usually considered for the modeling of water infiltration experiments (Lassabatere et al., 2009; Šimůnek and van Genuchten, 1997). We verified that the modeled infiltration bulb remained within the numerical domain, thus validating the low influence of boundary conditions on the modeled results. The hydraulic functions are computed considering van Genuchten (1980) model along with Mualem condition for the water retention curve and the Mualem (1976) model for the unsaturated hydraulic conductivity. The residual water contents were considered negligible (coarse material). The saturated water contents were equaled to the measure of porosity derived from the measure of bulk density on the site. Then, their related scale and shape parameters, $v=\left\{K_{s}, \alpha, n\right\}$, were then optimized by minimizing the objective function expressed in Eq. (17). $K_{s}$ is the saturated hydraulic conductivity, $\alpha$ is the scale parameter for water pressure head, and $n$ the shape parameter that rules the water retention curve.

\subsection{Hydrological classification of permeable pavements}

The estimates of the saturated hydraulic conductivity were used to compute infiltration indicators and classify the samples in regards to their infiltration capabilities as follows. The Soil Conservation Service (SCS) methodology, developed by the United States Department of Agriculture (USDA), groups the soils into four major classes that are hydrologically distinct in terms of infiltration capacity and surface runoff generation (Rawls et al., 1992). The identification of soil types involves the field saturated hydraulic conductivity, $K_{s f}$, as shown in Table 2. In our case, we considered that the estimated values of the saturated hydraulic conductivity equaled the values of the field saturated hydraulic conductivity, $K_{s}=K_{s f}$. Terzaghi et al. (1996) and Lambe and Whitman (1991) proposed to classify soils regarding the degree of permeability, or grade of permeability (GP), this being determined directly as function of the saturated hydraulic conductivity Table 3 . We used both classifications to compare the samples.

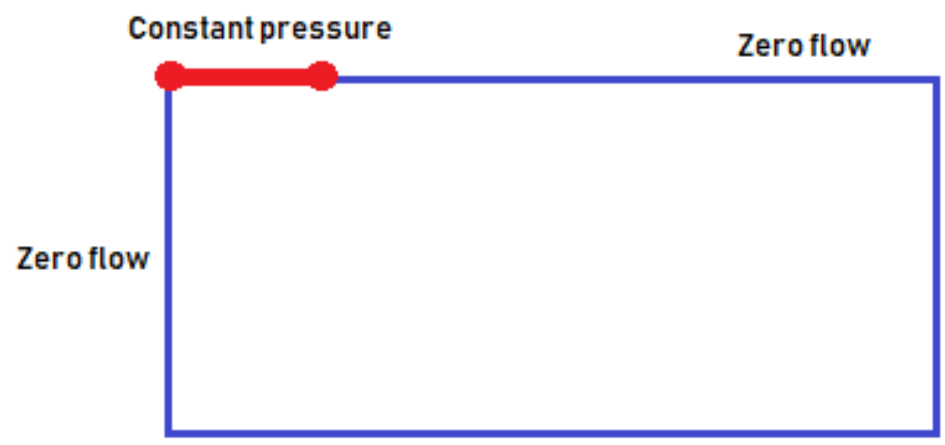

Free drainage
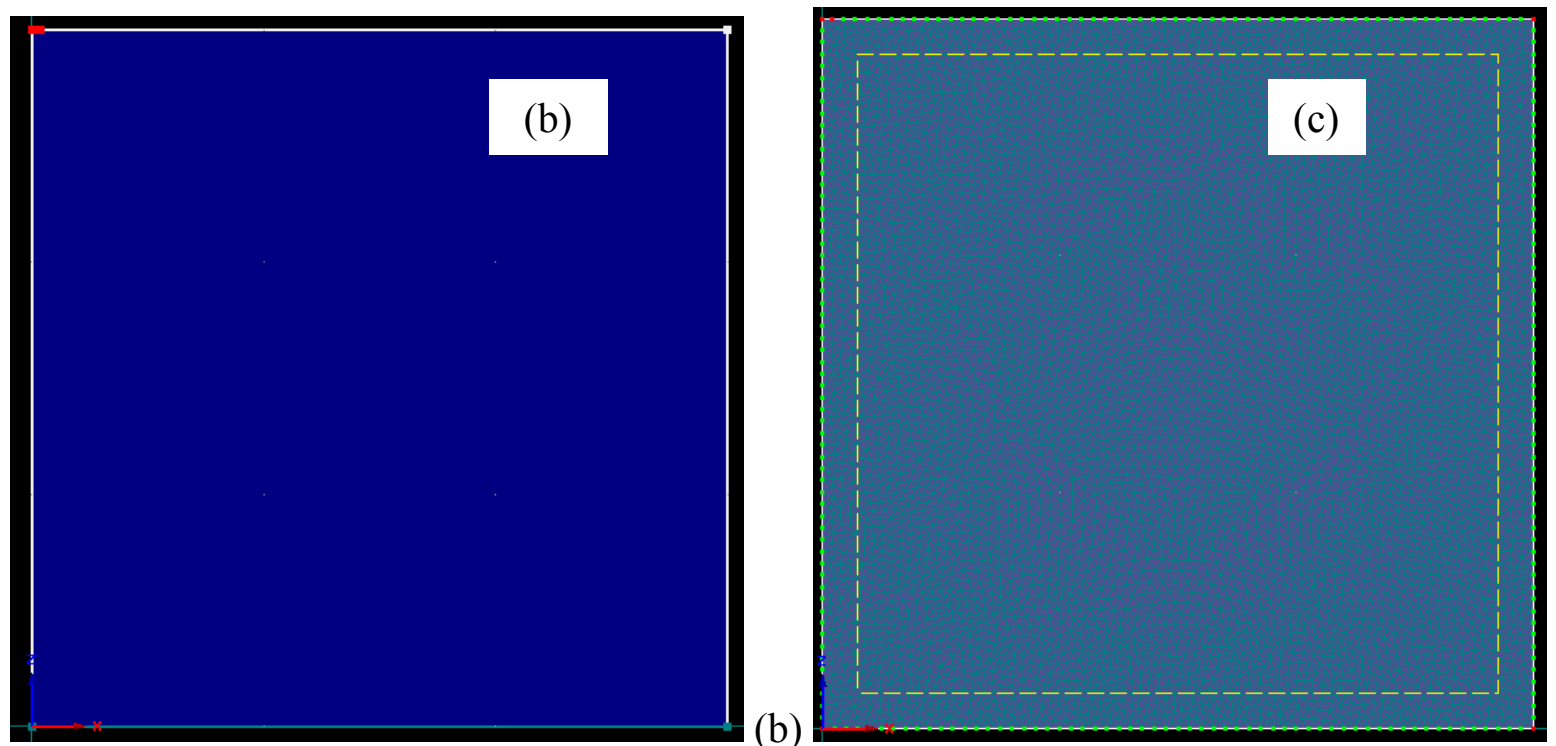

(c)

Fig. 3. Boundary conditions ( $\mathrm{a}$ - schematic view, b - real size) and (c) mesh used for the numerical modeling (with Hydrus). 
Table 2. Soil hydrological classification.

\begin{tabular}{lll}
\hline $\begin{array}{l}\text { Soil hydrological } \\
\text { classification }\end{array}$ & $\begin{array}{l}\text { Saturated hydraulic } \\
\text { conductivity }\left(\mathrm{mm} \mathrm{h}^{-1}\right)\end{array}$ & \multicolumn{1}{c}{ Characteristics } \\
\hline CLASS A & $K_{s f} \geq 7.6$ & $\begin{array}{l}\text { Soils that produce low runoff and high infiltration. Deep, sandy soils, with low } \\
\text { silt and clay content. }\end{array}$ \\
\hline CLASS B & $3.8 \leq K_{s f}<7.6$ & $\begin{array}{l}\text { Less permeable soils than the previous one, sandy soils less deep than group A } \\
\text { and with higher-than-average permeability. }\end{array}$ \\
\hline CLASS C & $1.3 \leq K_{s f}<3.8$ & $\begin{array}{l}\text { Soils that generate runoff above average and with infiltration capacity below } \\
\text { average, shallow, containing a considerable percentage of clay. }\end{array}$ \\
\hline CLASS D & $K_{s f}<1.3$ & Soils containing shallow, expansive clays with very low permeability \\
\hline
\end{tabular}

Table 3. Classification of soils according to the degree of permeability.

\begin{tabular}{lc}
\hline Degree of permeability & $\begin{array}{c}\text { Saturated hydraulic } \\
\text { conductivity }\left(\mathrm{mm} \mathrm{h}^{-1}\right)\end{array}$ \\
\hline High & 3600.00 \\
Medium & 36.00 \\
Low & 0.3600 \\
Very low & 0.0036 \\
Practically impermeable & $<0.0036$ \\
\hline
\end{tabular}

\subsection{Maintenance hydrodynamic indicator}

To verify the need of maintenance for the permeable pavement, we computed the hydrodynamic maintenance indicator (HMI) which involves the weighted average between the hydraulic conductivities obtained by the unidimensional and three-dimensional models and the infiltrated blades, according to the following equation:

$I H M=\frac{K_{1 D} \cdot L_{1 D}+K_{3 D} \cdot L_{3 D}}{L_{1 D}+L_{3 D}}$

where, $K_{1 D}$ is the hydraulic conductivity obtained in the onedimensional model; $K_{3 D}$ is the hydraulic conductivity obtained in the three-dimensional model; $L_{1 D}$ estimated infiltrated blade obtained in the one-dimensional model; $L_{3 D}$ is the estimated infiltrated blade obtained in the three-dimensional model.

\subsection{Statistical criteria for analyzing the quality of adjustments}

For each model fits to experimental data, coefficients and statistical criteria were obtained to determine the quality of the adjustments to the models. The determination coefficient $\left(\mathrm{R}^{2}\right)$ assesses the variance explained by the model. The closer to 1 , the better the model explains the observed data. The deviation ratio (DR) describes the ratio between the dispersion of observed and modeled values, also ensuring the best performance for values approaching 1 . The modeling efficiency (ME) indicates whether the model provides a better prediction than the average of observations, and should be close to 1 . The residual mass coefficient (RMC) tends to zero in the absence of deviations between observed and modeled values, indicating whether there is overestimation (RMC $>0$ ) or underestimation (RMC $<0$ ) of the model. The equations for the computation of $\mathrm{R}^{2}, \mathrm{RD}$, $\mathrm{ME}$ and RMC read as follows:

$$
R^{2}=\frac{\sum\left(\hat{y}_{i}-\overline{\hat{y}}\right)\left(y_{i}-\bar{y}\right)}{\sqrt{\sum\left(\hat{y}_{i}-\overline{\hat{y}}\right)^{2}} \sqrt{\sum\left(y_{i}-\bar{y}\right)^{2}}}
$$

$$
\begin{aligned}
& D R=\frac{\sum\left(\hat{y}_{i}-\bar{y}\right)^{2}}{\sum\left(y_{i}-\bar{y}\right)^{2}} \\
& M E=\frac{\sum\left(y_{i}-\bar{y}\right)^{2}-\sum\left(\hat{y}_{i}-y_{i}\right)^{2}}{\sum\left(y_{i}-\bar{y}\right)^{2}} \\
& R M C=\frac{\sum \hat{y}_{i}-y_{i}}{\sum y_{i}}
\end{aligned}
$$

where $y_{i}$ and $\hat{y}_{i}$ correspond to observed and modeled data, respectively. The expressions of $\mathrm{R}^{2}, \mathrm{ME}$ and $\mathrm{RMC}$ can be found in (Baloch et al., 2015). We added an additional parameter, referred to as Deviation Ratio (DR) that gives an insight on the difference between the modeled and observed data in terms of standard deviations.

\section{RESULTS AND DISCUSSION}

The cumulative infiltrations treated in this study were extracted from the study of Coutinho et al. (2016). The 52 cumulative infiltrations were obtained at the same time and for similar experimental conditions. The beam of experimental curves reflects a significant variability (Fig. 4), despite similar experimental conditions and settlement of the CGP elements. Such variability was related by Coutinho et al. (2016) to the soil texture, with four different classes of soils: silt, sandy silt, silty sand, and sand. Other factors seem to interfere as well, with disturbance of the expected order between soil texture for some tests. We may expect differential compaction between voids, root-induced macropore and related preferential flows, clogging of the surface with the deposition of organic matter (leaves from

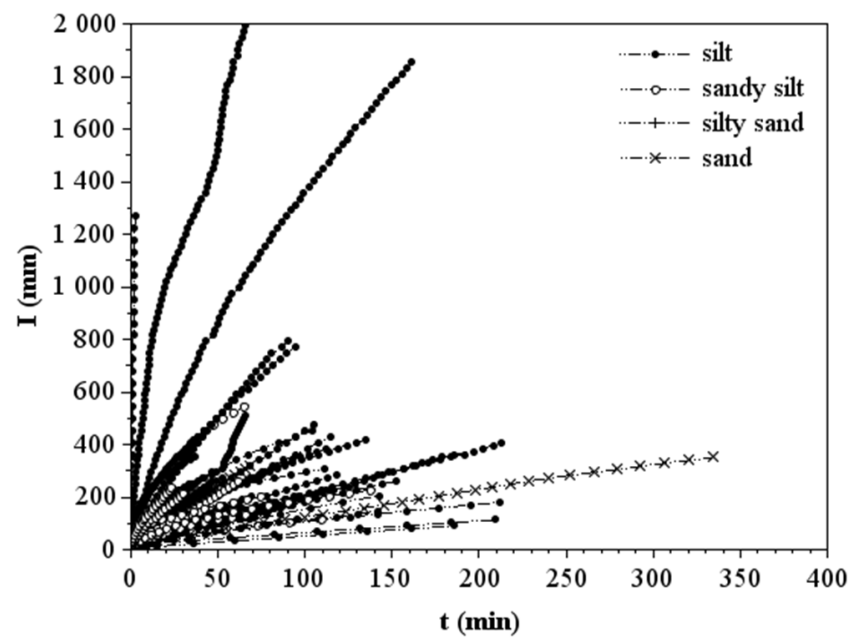

Fig. 4. Cumulative infiltrations obtained on the field by Coutinho et al. (2016). 
trees nearby), etc. Despite that variability, most of the curves exhibit regular shapes, with a first concave shape corresponding to the transient state followed by the steady-state (final linear part) (Angulo-Jaramillo et al., 2016). The very fast infiltration provided linear shapes with a very short transient state.

\subsection{Analysis of the steady state of infiltration with analytical models}

For the 52 tested points, a linear regression analysis of the $(I, t)$ data collected during the steady-state phase of the infiltration run was performed. The most common cases of adjustments to the steady methods are presented in Fig. 5 and Fig. 6, respectively for the SSBI method and $\mathrm{Wu} 2$. The graphs shown in Fig. 5a, Fig. 5b, Fig. 6a and Fig. 6b correspond to points P3, P17, P28 and P52, respectively, and are illustrative of main results with good fits of the model to the experimental data. The Wu 2 method presented excellent fits to the experimental cumulative infiltration curves for practically all the runs.

The statistical summary of the hydraulic parameters obtained, $\alpha^{*}$ and $K_{s}$, are presented in Table 4 for the two methods. The values of $K_{s}$ have an average of $56.32 \mathrm{~mm} \mathrm{~h}^{-1}$ to SSBI method and $69.50 \mathrm{~mm} \mathrm{~h}^{-1}$ to $\mathrm{Wu} 2$ method. For the SSBI method, the values of $K_{s}$ ranged from 0.00979 to $521.8 \mathrm{~mm} \mathrm{~h}^{-1}$, and for the $\mathrm{Wu} 2$ method the values ranged from $2.39 \mathrm{~mm} \mathrm{~h}^{-1}$ and $397.40 \mathrm{~mm} \mathrm{~h}^{-1}$. SSBI method showed higher variability $(\sigma=$ $\left.75.42 \mathrm{~mm} \mathrm{~h}^{-1}\right)$ than $\mathrm{Wu} 2$ method $\left(\sigma=67.18 \mathrm{~mm} \mathrm{~h}^{-1}\right)$. SSSBI exhibited a moderate positive asymmetric distribution with coefficient of variation of 1.339 whereas the $\mathrm{Wu} 2$ method presented strong positive asymmetric distribution. The asymmetries can be observed in the graph of Fig. 7. It shows a moderate amplitude, with a few outliers (mostly high values). It was possible to observe that although the selection of the datapoints for steady state was the same for the two methods, the

a)

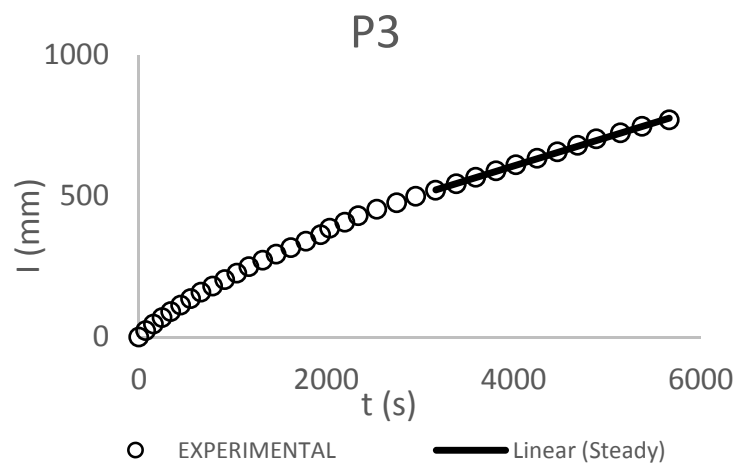

results were results method dependence despite similar means and medians (Fig. 7). The values of the saturated hydraulic conductivity calculated by SSBI method were lower than those obtained by $\mathrm{Wu} 2$. The high variability of the results for the two methods also indicates the heterogeneity of the infiltration capacity between points. As discussed above, such a variation may result from different soil texture and soil structure in relation to different levels of soil compaction. This may be due to several factors, such as different levels of loading and compaction of the pavement, the effect of the grass, but also the presence and quantity of material deposited at the soil surface, such as leaves and other types of organic matter and sediments in general. Indeed, the soil type and conditions at the surface, in particular clogging, may change water infiltration drastically (Lassabatere et al., 2010). On the opposite, the development of root systems and any type of bioturbation may trigger preferential flow with the creation of a fast-flow zone in addition to matrix flow (Kodešová et al., 2006; Lassabatere et al., 2014).

Despite high variability of saturated hydraulic conductivity observed in the SSBI method, the hydrological classification of the soil is the same according to the hydrological classification methodologies used (Table 5). In the SCS (Soil Conservation Service) classification, the points were classified $(92.31 \%)$ as "class A," characterized by low surface flow and high infiltration capacity. In the GP classification, a little more than $50 \%$ of the PP was evaluated with "low" GP, while about $46 \%$ was classified as "medium". Analyzing the Wu 2 method the classification of the coating by the SCS methodology was essentially the same, "Class A" soil, because the saturated hydraulic conductivity of the soil was higher than $7.6 \mathrm{~mm} \mathrm{~h}^{-1}$. In the GP classification, $69.23 \%$ of the tests were assigned the "Medium" concept for PP permeability (Table 6). This indicates the possible need for interventions to reestablish the infiltration capacity of the system. b)

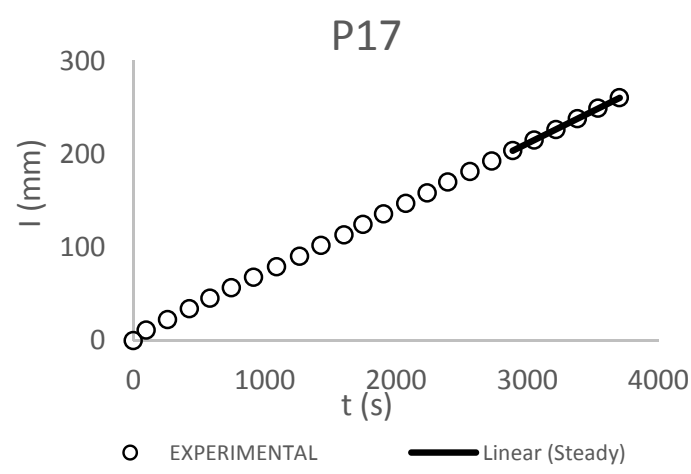

Fig. 5. Examples of linear regression of infiltration data $(t, I)$ at steady-state for the SSBI method.

a)

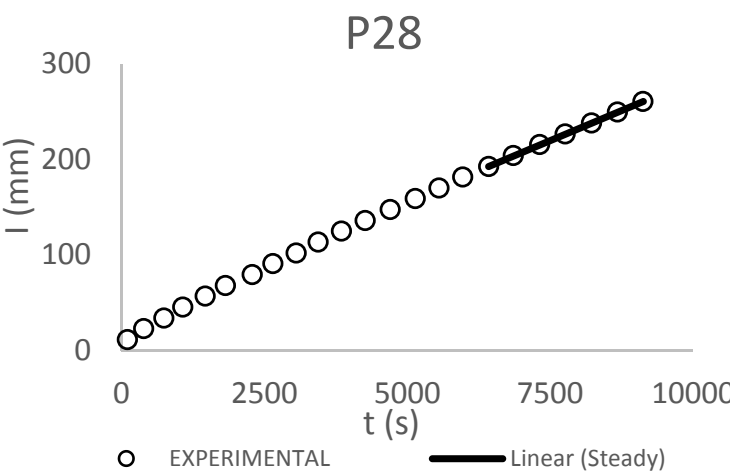

b)

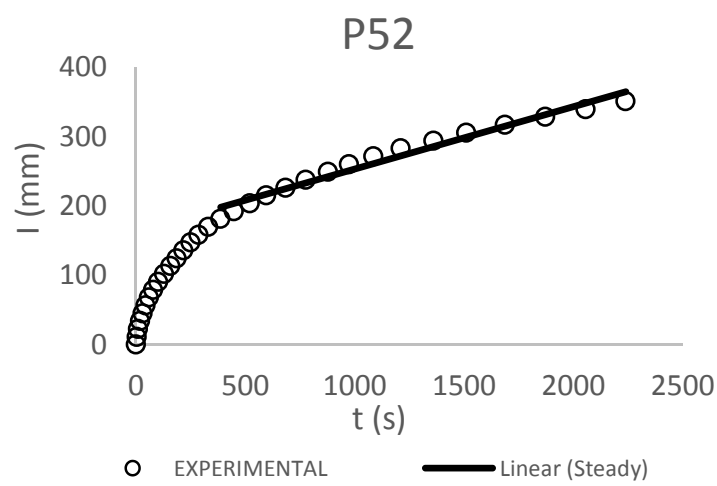

Fig. 6. Examples of linear regression of infiltration data $(t, I)$ at steady-state for the $\mathrm{Wu} 2$ method. 
Table 4. Estimates of the hydraulic parameters obtained with the SSBI Method and the Wu 2 method.

\begin{tabular}{lccc}
\hline & & SSBI & Wu 2 \\
\cline { 2 - 3 } Statistic & $\alpha^{*}\left(\mathrm{~cm}^{-1}\right)$ & $K_{s}\left(\mathrm{~mm} \mathrm{~h}^{-1}\right)$ & $K_{s}\left(\mathrm{~mm} \mathrm{~h}^{-1}\right)$ \\
\hline Minimum & 0.02086 & 0.009793 & 392 \\
Maximum & 0.4088 & 521.8 & 397.4 \\
Average & 0.1235 & 56.32 & 69.49 \\
Standard deviation $(\sigma)$ & 0.0678 & 75.42 & 67.18 \\
Coefficient of variation $(\mathrm{CV})$ & 0.5489 & 1.339 & 0.967 \\
\hline
\end{tabular}

Table 5. Hydrological classification of the coating considering the results from the SSBI Method (FF: frequency).

\begin{tabular}{|c|c|c|c|c|c|}
\hline \multicolumn{6}{|c|}{ SSBI Method } \\
\hline \multicolumn{3}{|c|}{ SCS } & \multicolumn{3}{|c|}{ GP } \\
\hline Criteria & $\mathrm{FF}$ & $\%$ & Criteria & FF & $\%$ \\
\hline Class A & 48 & 92.31 & High & 0 & 0.00 \\
\hline Class B & 2 & 3.85 & Medium & 24 & 46.15 \\
\hline Class $\mathrm{C}$ & 1 & 1.92 & Low & 27 & 51.92 \\
\hline \multirow[t]{2}{*}{ Class D } & 1 & 1.92 & Very Low & 1 & 1.92 \\
\hline & & & Practically Impermeable & 0 & 0.00 \\
\hline
\end{tabular}

Table 6. Hydrological classification of the coating considering the results from the $\mathrm{Wu} 2$ method.

\begin{tabular}{|c|c|c|c|c|c|}
\hline \multicolumn{6}{|c|}{ Wu 2 Method (FF: frequency) } \\
\hline \multicolumn{3}{|c|}{ SCS } & \multicolumn{3}{|c|}{ GP } \\
\hline Criteria & $\mathrm{FF}$ & $\%$ & Criteria & $\mathrm{FF}$ & $\%$ \\
\hline Class A & 50 & 96.15 & High & 0 & 0.00 \\
\hline Class B & 1 & 1.92 & Medium & 36 & 69.23 \\
\hline Class C & 1 & 1.92 & Low & 16 & 30.77 \\
\hline \multirow[t]{2}{*}{ Class D } & 0 & 0.00 & Very Low & 0 & 0.00 \\
\hline & & & Practically Impermeable & 0 & 0.00 \\
\hline
\end{tabular}

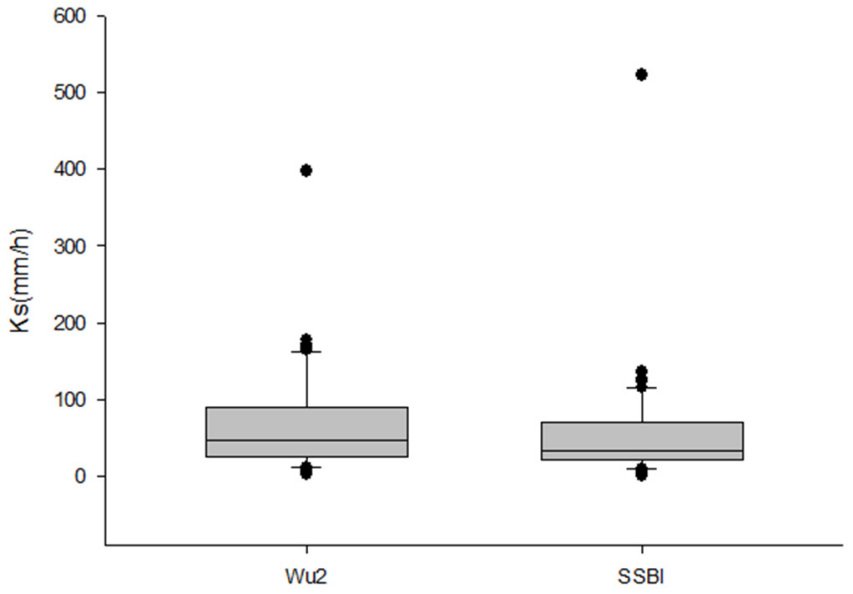

Fig. 7. Boxplot for the $K_{s}$ parameter for SSBI and Wu 2 methods.

\subsection{Analysis of the transient state of infiltration with analytical models}

The saturated hydraulic conductivity of $\mathrm{Wu} 1$ method was optimized by fitting the entire accumulated infiltration curve (see Figure 8 for examples of fits). The overall statistical analysis of the goodness of fits shows an average correlation coefficient $\left(\mathrm{R}^{2}\right)$ near the unit (Table 7). This indicates that the model related to $\mathrm{Wu} 1$ method satisfactorily fit the data collected in the field. The mean deviation ratio (RD) and the modeling efficiency (ME) have values close to the unity, confirming the quality of the fits. The mean residual mass coefficient (RMC) has a null averaged value, but its analysis indicates that the model has a slight tendency to underestimate $(\mathrm{RMC}<0)$ in $34.7 \%$ of the cases and overestimate in other cases.
The statistical results for the estimates of $K_{s}$ and $\alpha$ provided by the $\mathrm{Wu} 1$ method are presented in Table 8 . The estimates of $\alpha$ vary between 0.003 and $1.150 \mathrm{~cm}^{-1}$, with an average of 0.125 $\mathrm{cm}^{-1}$, which is compatible with the expected value this type of soil, i.e., a sandy loam (Wu et al., 1999). The coefficient of variation (CV) of $188.4 \%$ confirms the heterogeneity among the samples. Regarding the saturated hydraulic conductivity, the minimum value is in the order of $0.009 \mathrm{~mm} \mathrm{~h}^{-1}$ for a maximum of $153.0 \mathrm{~mm} \mathrm{~h}^{-1}$, with a coefficient of variation of $118.7 \%$. Our estimations for $K_{s}$ are compatible with previous works and in particular those obtained by Xu et al. (2012) for the same type of soil. However, we found slightly higher values for $\alpha$.

For 3 of 52 points, the Wu 1 method did not work and provided null values for $K_{s}$. According to Xu et al. (2012), those cases occur due to the values of the coefficient A in Eq. (6) inducing wrong values of variable $\mathrm{C}$ leading to negative sign of the right-hand side of Eq. (7). Those results were obtained infiltration curves presenting two contrasting parts corresponding to different slopes. Such pattern may point at the succession of two different flow regimes, corresponding to different physics of water infiltration (like water infiltration into layered profiles). The hydrological classification (SCS) classified most of the coating samples as "class A" regarding SCS criteria. The permeability of PP was considered "Low" $(<0.36 \mathrm{~mm} / \mathrm{h})$ in more than $65 \%$ of the analyzed cases, based on the GP sorting (Table 9).

\subsection{One-dimensional models adapted to 3D}

The experimental curves were fitted to the five different onedimensional models studied in this article: the Philip model (Philip, 1957), the Stroosnijder model (Stroosnijder, 1976), the 
a)

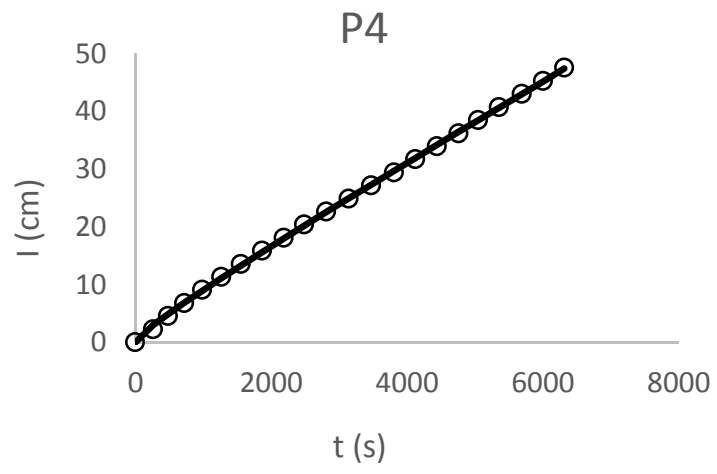

c)

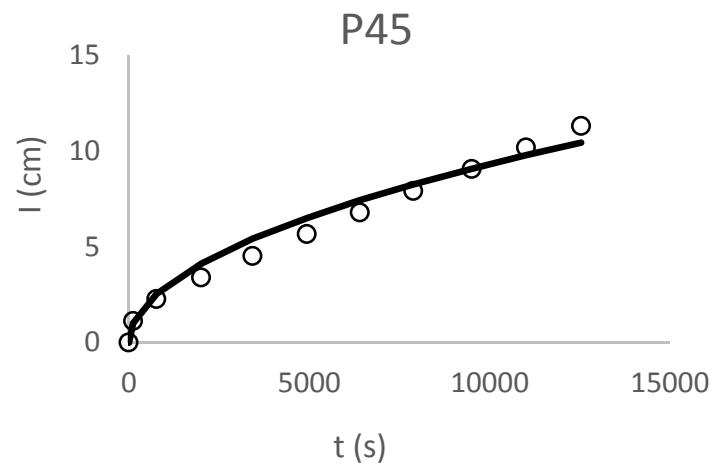

b)

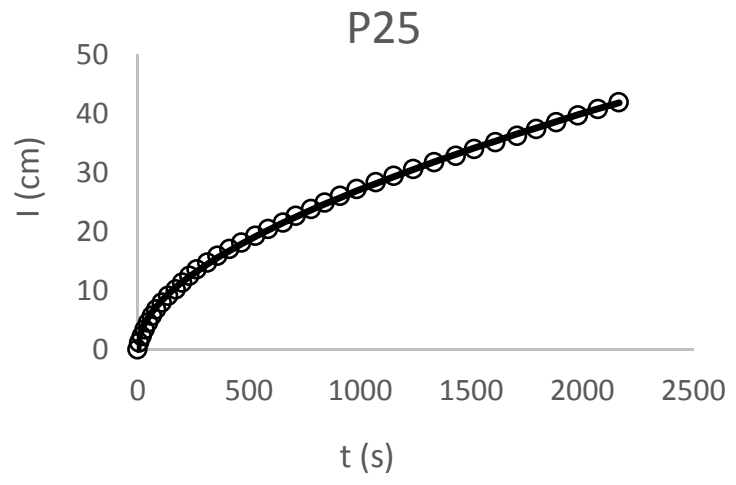

d)

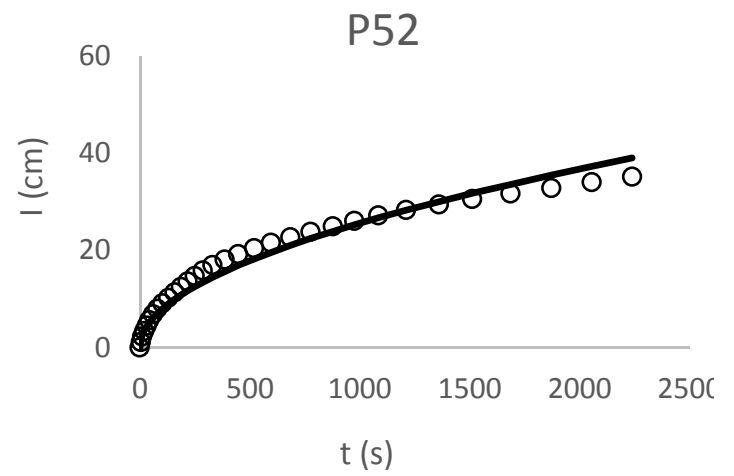

Fig. 8. Examples of fits of infiltration data $(t, I)$ for the $\mathrm{Wu} 1$ method. a) and b) illustrative the case of excellent fits; c) and d) illustrative examples of rare cases with poor fits due to extra or specific concavity of the experimental data.

Table 7. Statistical analysis of fits related to the Wu 1 method.

\begin{tabular}{lcccc}
\hline Statistic & $\mathrm{R}^{2}$ & $\mathrm{DR}$ & $\mathrm{RMC}$ & $\mathrm{ME}$ \\
\hline Minimum & 0.980 & 0.856 & -0.032 & 0.967 \\
Maximum & 1.000 & 1.142 & 0.035 & 1.000 \\
Average & 0.997 & 1.002 & 0.000 & 0.996 \\
Standard deviation $(\sigma)$ & 0.004 & 0.052 & 0.010 & 0.007 \\
\hline
\end{tabular}

Table 8. Estimates of the hydraulic parameters obtained with the $\mathrm{Wu} 1$ method.

\begin{tabular}{lcc}
\hline Statistic & $K_{s}\left(\mathrm{~mm} \mathrm{~h}^{-1}\right)$ & $\alpha\left(\mathrm{cm}^{-1}\right)$ \\
\hline Minimum & 0.009 & 0.003 \\
Maximum & 153.099 & 1.150 \\
Average & 24.243 & 0.125 \\
Standard deviation $(\sigma)$ & 28.781 & 0.236 \\
Coefficient of variation $(\mathrm{CV})$ & 1.187 & 1.884 \\
\hline
\end{tabular}

Table 9. Hydrological classification of the coating considering the results from the Wu 1 method.

\begin{tabular}{lcc|lcc}
\hline & \multicolumn{2}{c|}{ SCS } & \multicolumn{3}{c}{ GP } \\
\hline Criteria & FF & $\%$ & Criteria & FF & 0 \\
\hline Class A & 34 & 69.39 & High & 14 & 0.00 \\
Class B & 4 & 8.16 & Medium & 34 & 28.57 \\
Class C & 5 & 10.20 & Low & 1 & 69.39 \\
Class D & 6 & 12.24 & Very Low & 0 & 2.04 \\
& & & Practically Impermeable & 0.00 \\
\hline
\end{tabular}

Knight soil model by Philip and Knight (1974), the Brutsaert model (1977), and the Swartzendruber model (1987). Table 10 presents the statistical analysis of the goodness of fits for these models. In general, all one-dimensional models were efficient in fitting the experimental data with correlation coefficient $\left(\mathrm{R}^{2}\right)$ close to 1 . The Deviation Ratio (DR) exhibited quite low averages, between $0.5 \%$ for the Philip model and $2 \%$ for Brutsaert model, proving the quality of the fits, despite some large devia- tions (e.g., 18.6\%, for Brutsaert model). All the ME were close to 1.0 with very low standard deviations. The RMC values were close to zero in most cases, denoting unbiased fits, except for Philip model with overestimation in more than $56 \%$ of the analyzed trials. Briefly, the fit using the one-dimensional models adapted to $3 \mathrm{D}$ water infiltration can be considered as very satisfying. 
Effect of the choice of different methods on the permeable pavement hydraulic characterization and hydrological classification

Table 10. Statistical analysis of fits related to one-dimensional models: mean and standard deviation $(\mathrm{n}=52)$.

\begin{tabular}{|c|c|c|c|c|c|c|c|c|c|c|}
\hline \multirow[t]{2}{*}{ Criteria } & \multicolumn{2}{|c|}{$\begin{array}{l}\text { Philip } \\
\text { (1957) }\end{array}$} & \multicolumn{2}{|c|}{$\begin{array}{c}\text { Stroosnijder } \\
(1976)\end{array}$} & \multicolumn{2}{|c|}{$\begin{array}{c}\text { Knight soil Philip } \\
\text { (1974) }\end{array}$} & \multicolumn{2}{|c|}{$\begin{array}{c}\text { Brutsaert } \\
(1977)\end{array}$} & \multicolumn{2}{|c|}{$\begin{array}{c}\text { Swartzendruber } \\
(1987)\end{array}$} \\
\hline & $\mu$ & $\sigma$ & $\mu$ & $\sigma$ & $\mu$ & $\sigma$ & $\mu$ & $\sigma$ & $\mu$ & $\sigma$ \\
\hline \multicolumn{11}{|c|}{ Statistical Criteria } \\
\hline $\mathrm{R}^{2}$ & 0.9976 & 0.0039 & 0.9980 & 0.0032 & 0.9980 & 0.0033 & 0.9980 & 0.0034 & 0.9980 & 0.0031 \\
\hline DR & 0.9951 & 0.0514 & 1.0180 & 0.0372 & 1.0180 & 0.0366 & 1.0200 & 0.0393 & 1.0120 & 0.0327 \\
\hline $\mathrm{RMC}$ & -0.0019 & 0.0097 & 0.0020 & 0.0051 & 0.0020 & 0.0051 & 0.0020 & 0.0052 & 0.0010 & 0.0045 \\
\hline ME & 0.9963 & 0.0063 & 0.9970 & 0.0042 & 0.9970 & 0.0042 & 0.9970 & 0.0045 & 0.9980 & 0.0039 \\
\hline
\end{tabular}

Table 11. Estimates of the hydrodynamic parameters, $K_{S}$ and $S$ obtained by fitting one-dimensional models.

\begin{tabular}{lccccc}
\hline \multirow{2}{*}{ Statistic } & \multicolumn{3}{c}{$K_{s}\left(\mathrm{~mm} \mathrm{~h}^{-1}\right)$} \\
\cline { 2 - 6 } & Philip (1957) & $\begin{array}{c}\text { Stroosnijder } \\
(1976)\end{array}$ & $\begin{array}{c}\text { The Knight soil } \\
\text { Philip (1974) }\end{array}$ & $\begin{array}{c}\text { Brutsaert } \\
(1977)\end{array}$ & $\begin{array}{c}\text { Swartzendruber } \\
(1987)\end{array}$ \\
\hline Minimum & 13.456 & 21.269 & 23.484 & 21.192 & 0.287 \\
Maximum & 472.307 & 619.204 & 557.175 & 696.999 & 408.311 \\
Average & 140.514 & 187.916 & 190.801 & 190.502 & 139.334 \\
Standard deviation $(\sigma)$ & 105.587 & 133.729 & 135.635 & 139.065 & 98.238 \\
Coefficient of variation $(\mathrm{CV})$ & 0.751 & 0.712 & 0.711 & 0.730 & 0.705 \\
\hline \multicolumn{1}{c}{-} & 2.480 & 2.881 & 2.925 & 3.017 & 2.702 \\
\hline Average & 3.568 & 3.654 & 3.762 & 3.795 & 3.598 \\
Standard deviation $(\sigma)$ & 1.439 & 1.268 & 1.286 & & 1.258 \\
Coefficient of variation $(\mathrm{CV})$ & & & & & 1.331 \\
\hline
\end{tabular}

The related hydrodynamic parameters are shown in Table 11. The $K_{s}$ averaged value derived from the Philip model (140.5 $\left.\mathrm{mm} \mathrm{h}^{-1}\right)$ and Swartzendruber model $\left(139.3 \mathrm{~mm} \mathrm{~h}^{-1}\right)$ were very close. Such a proximity was linked to the fact that the Swartzendruber model was derived from the temporal series proposed by Philip model (Swartzendruber, 1987). However, the range of extremes, minimum and maximum values of $K_{s}$ was higher for the Philip model. The standard deviation was $105.6 \mathrm{~mm} \mathrm{~h}^{-1}$ corresponding to a coefficient variation of $75.1 \%$, being the highest among all the used one-dimensional models. Meanwhile, the $K_{s}$ parameters derived from the Swartzendruber model presented the lowest standard deviation among the onedimensional models, with a value of $70.5 \%$ for the coefficient of variation. For the Stroosnijer, the Knight Soil Philip and Brutsaert model, the average for saturated hydraulic conductivity were close to $190 \mathrm{~mm} \mathrm{~h}^{-1}$, standard deviations in the order of $135 \mathrm{~mm} \mathrm{~h}^{-1}$ and coefficients of variation around $71 \%$. In terms of asymmetry, the distribution of estimates presents moderate asymmetry for the five one-dimensional models.

Regarding the sorptivity $(S)$, the average values have the same order of magnitude, varying between $2.480 \mathrm{~mm} \mathrm{~s}^{-1 / 2}$ for the Philip model and $3.017 \mathrm{~mm} \mathrm{~s}^{-1 / 2}$ for the Brutsaert model (Table 11). The variability of $S$ was greater than for the parameter $K_{s}$, with standard deviation equaling $131 \%$ of the averaged values. These results ratify the heterogeneity of the infiltration capacity at the scale of the permeable pavement. The $K_{s}$ values estimated by the one-dimensional infiltration models were plotted in parallel box-plot. This allowed the graphical comparison of the measurements sets concerning the average, dispersion and distribution (Fig. 9).

All models have the same order of magnitude for $K_{s}$, with averages varying between $139.33 \mathrm{~mm} \mathrm{~h}^{-1}$ (Swartzendruber model) and $190.8 \mathrm{~mm} \mathrm{~h}^{-1}$ for the Knight Soil Philip model. Regarding the dispersion of the data, represented by the amplitude of the boxplot (Fig. 9), the models of Philip model and Swartzendruber model show lower deviations. While the hydraulic conductivity estimated by the Knight Soil Philip model are subject to the greatest variations. Despite this, there is no significant dependence of $K_{s}$ values on the choice of one-

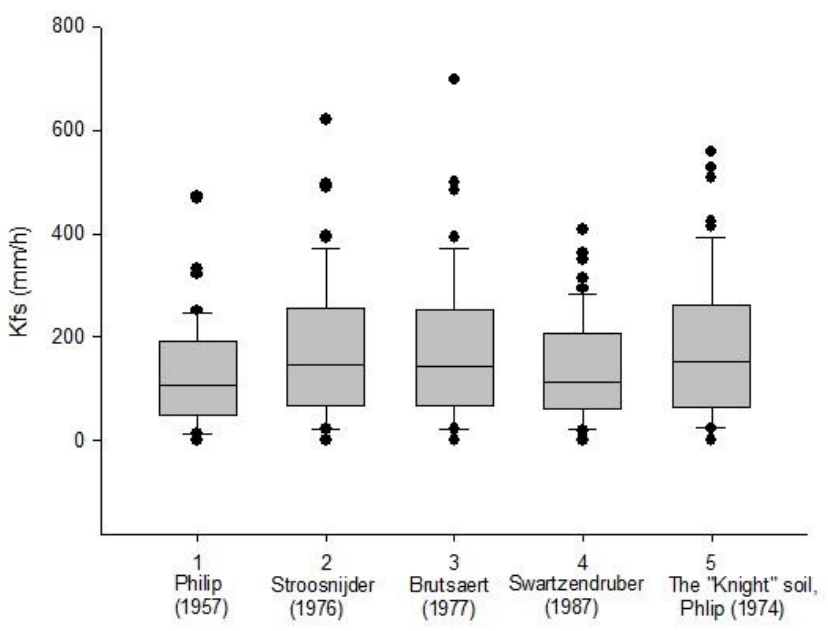

Fig. 9. Boxplot of the saturated hydraulic conductivity parameter for the theoretical models of one-dimensional infiltration adapted to $3 \mathrm{D}$.

dimensional model to invert cumulative infiltrations. For all analyzed cases, the empirical distribution of the data was positive asymmetric with the presence of outliers, represented in the graphs by the dots outside the upper and lower limits of the box. Outliers indicate the specific existence of extreme cases, such as partial/total obstruction of PP, with abrupt reduction of permeability (outliers below the box). It can also represent the appearance of preferential pathways draining the infiltrated water, resulting in an increase in infiltration flux and outliers above the box.

The qualitative analysis of the hydraulic parameters, performed through the hydrological classification of the coating (SCS), permeability degree, or grade of permeability (GP), and the hydrodynamic maintenance indicator (HMI), is presented in Table 12. The values of $K_{s}$ estimated by the one-dimensional models are of the order of 100 times higher than the $K_{s}$ estimated by the methods $\mathrm{Wu} 1, \mathrm{Wu} 2$, and SSBI. Such a gap may result from the adaptation of the one-dimensional models to $3 \mathrm{D}$ 
Table 12. Hydrological classification (SCS), degree of permeability (GP) and hydrodynamic maintenance indicator (HMI) obtained with results from the fits to one-dimensional models (FF: frequency).

\begin{tabular}{|c|c|c|c|c|c|c|c|c|c|c|}
\hline \multirow[t]{2}{*}{ Criteria } & \multicolumn{2}{|c|}{$\begin{array}{l}\text { Philip } \\
\text { (1957) }\end{array}$} & \multicolumn{2}{|c|}{$\begin{array}{c}\text { Stroosnijder } \\
(1976)\end{array}$} & \multicolumn{2}{|c|}{$\begin{array}{l}\text { Knight soil Philip } \\
\text { (1974) }\end{array}$} & \multicolumn{2}{|c|}{$\begin{array}{l}\text { Brutsaert } \\
\text { (1977) }\end{array}$} & \multicolumn{2}{|c|}{$\begin{array}{l}\text { Swartzendruber } \\
\text { (1987) }\end{array}$} \\
\hline & FF & $\%$ & FF & $\%$ & FF & $\%$ & FF & $\%$ & FF & $\%$ \\
\hline \multicolumn{11}{|l|}{ SCS } \\
\hline Class A & 48 & 100.0 & 47 & 100.0 & 47 & 100.0 & 48 & 100.0 & 49 & 98.0 \\
\hline Class B & 0 & 0.0 & 0 & 0.0 & 0 & 0.0 & 0 & 0.0 & 0 & 0.0 \\
\hline Class C & 0 & 0.0 & 0 & 0.0 & 0 & 0.0 & 0 & 0.0 & 0 & 0.0 \\
\hline Class D & 0 & 0.0 & 0 & 0.0 & 0 & 0.0 & 0 & 0.0 & 1 & 2.0 \\
\hline \multicolumn{11}{|c|}{ GP } \\
\hline High & 0 & 0.0 & 0 & 0.0 & 0 & 0.0 & 0 & 0.0 & 0 & 0.0 \\
\hline Medium & 41 & 85.4 & 42 & 89.4 & 42 & 89.4 & 42 & 87.5 & 44 & 88.0 \\
\hline Low & 7 & 14.6 & 4 & 8.5 & 4 & 8.5 & 5 & 10.4 & 6 & 12.0 \\
\hline Very Low & 0 & 0.0 & 0 & 0.0 & 0 & 0.0 & 0 & 0.0 & 0 & 0.0 \\
\hline P. waterproof & 0 & 0.0 & 0 & 0.0 & 0 & 0.0 & 0 & 0.0 & 0 & 0.0 \\
\hline \multicolumn{11}{|c|}{ IHM } \\
\hline Clear & 0 & 0.0 & 0 & 0.0 & 0 & 0.0 & 0 & 0.0 & 0 & 0.0 \\
\hline Mod. Clear & 42 & 87.5 & 43 & 91.5 & 43 & 91.5 & 43 & 89.6 & 44 & 88.0 \\
\hline Partial. Clogged & 6 & 12.5 & 4 & 8.5 & 4 & 8.5 & 5 & 10.4 & 6 & 12.0 \\
\hline Total. Clogged & 0 & 0.0 & 0 & 0.0 & 0 & 0.0 & 0 & 0.0 & 0 & 0.0 \\
\hline
\end{tabular}

Table 13. Statistical analysis of the fits obtained with numerical inverse modeling.

\begin{tabular}{|c|c|c|c|c|}
\hline Statistic & $\mathrm{R}^{2}$ & $\overline{D R}$ & RMC & $\mathrm{ME}$ \\
\hline Minimum & 0.995 & 0.874 & -0.002 & 0.989 \\
\hline Maximum & 1.000 & 1.019 & 0.045 & 1.000 \\
\hline Average & 0.999 & 0.970 & 0.006 & 0.998 \\
\hline Standard deviation $(\sigma)$ & 0.001 & 0.031 & 0.008 & 0.002 \\
\hline
\end{tabular}

by adding the term related to radial infiltration. This point may be the subject of further investigations. The differences in estimates probably means significant changes regarding the classification of the same PP samples. Regarding the classification of the coating according to the SCS methodology, "class A" was obtained mostly for all tests with valid results. The surfaces classified in this SCS classification are characterized by low runoff and high infiltration capacity. The criterion defining "class $\mathrm{A} "\left(K_{s} \geq 7.6 \mathrm{~mm} \mathrm{~h}^{-1}\right)$ is a little restrictive because it is a classification created to characterize soil layers, and in that case, adapted to the PP. The degree of permeability of the coating (GP) was considered as "medium" in more than $80 \%$ of all analyzed cases, according to the permeability degree $\left(0.36 \mathrm{~mm} \mathrm{~h}^{-1}<\mathrm{GP}<36.0 \mathrm{~mm} \mathrm{~h}^{-1}\right)$. Therefore, there is a change in the PP permeability framing range, before referred to as "Low" and now referred to as "Medium". Regarding HMI classifications, mean values varied between $157.36 \mathrm{~mm} \mathrm{~h}^{-1}$ (Swartzendruber model) and 224, $29 \mathrm{~mm} \mathrm{~h}^{-1}$ (Knight Soil Philip model). The objective of the HMI is to assist in decision making for maintenance intervention and/or restoration of permeable pavement infiltration conditions. For all onedimensional models, the HMI indicated a "moderately obstructed" condition for the PP coating. This corresponds to a reduction in its initial infiltration capacity and the need to draw up a short-term surface maintenance plan up to maximal three years.

\subsection{Numerical inversion}

As detailed above, the inverse method simultaneously provided estimations of the parameters of the water retention curve and the hydraulic conductivity curve (including the parameters $K_{s}, n$ and $\alpha$ ) by fitting numerically the experimental cumulative infiltrations. We remind that the remaining parameters were derived from field measures: the residual water content was equaled to zero and the saturated water content was derived from the measure of bulk density. As depicted in Fig. 10, the fits were very good in most cases, despite the fact that some cases could be inverted without any possibility to obtain the hydrodynamic parameters for the runs P6, P9, P11, P15, P20, $\mathrm{P} 42$, and P52 (non-convergence of the numerical inversion). These cases were not considered hereafter. For the other tests, the fits were very accurate, with correlation coefficient $\left(\mathrm{R}^{2}\right)$ close to 1 (Table 13). The Deviation Ratio (DR) criterion had an average around $97 \%$ and a maximum deviation of $3.1 \%$, also indicating good performance of the inverse modelling. The average ME statistical criterion tended to 1.0 , with a very low standard deviation. The RMC criterion pointed at a light underestimation of the adjusted curves for more than $90 \%$ of the analyzed points. These statistics proved the efficiency of the numerical inverting procedure to obtain the hydraulic parameters of the infiltration.

The mean hydraulic conductivity of the saturated soil was estimated to be $0.327 \mathrm{~mm} \mathrm{~h}^{-1}$, with a standard deviation of $0.375 \mathrm{~mm} \mathrm{~h}^{-1}$ and coefficient of variation of $114.5 \%$ (Table 14). The sample distribution of the results was considered asymmetric and moderate. The mean values and standard deviation of the results were, 2.139 and 2.958 for $n$, and 0.029 and 0.045 $\mathrm{cm}^{-1}$ for $\alpha$, respectively. The parameters $n$ and $\alpha$ calculated by the inverse method are compatible with those obtained for silty sand (Coutinho et al., 2016) or loam silt material (Antonino et al., 2004). However, the variation coefficients for $n$ and $\alpha$ are larger than $100 \%$, indicating a large spread of the dispersion and thus a significant spatial variability.

The magnitude order of the results obtained for $K_{s}$ from the Inverse Method is about 100 times smaller than the values obtained with the analysis of the transient state with the onedimensional models adapted to 3D. The difference with the previous values may be surprising. The discrepancy between numerical inversion and BEST methods had already been discussed by previous authors (e.g., Yilmaz et al., 2013) and may 
a)

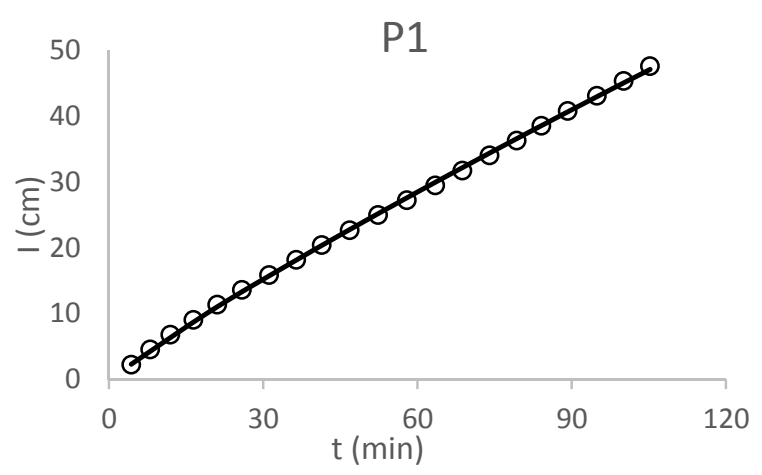

c)

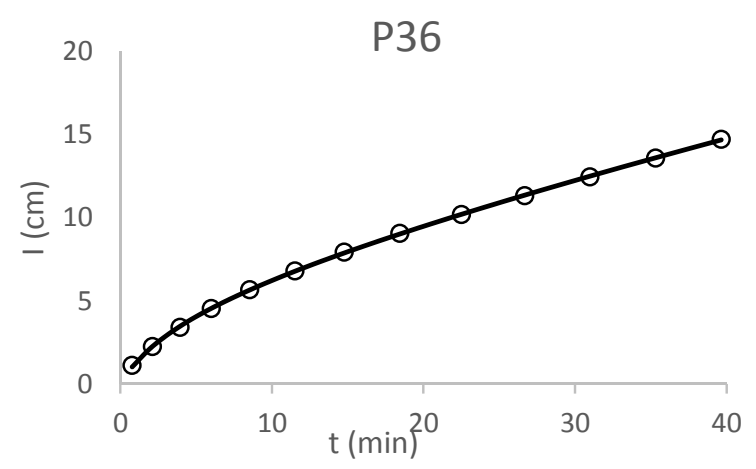

b)

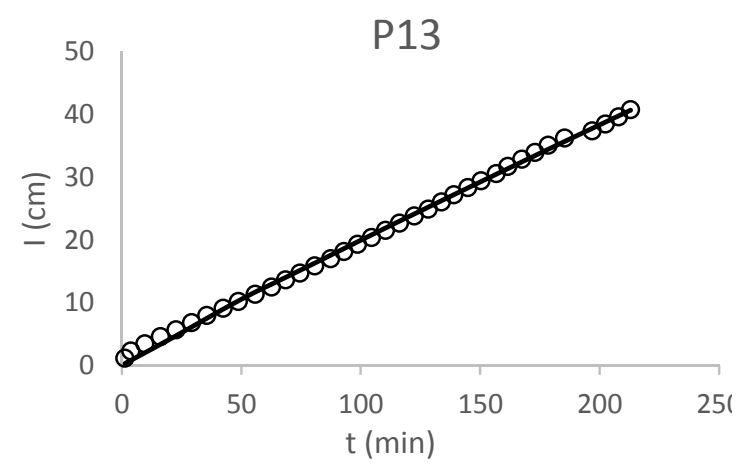

d)

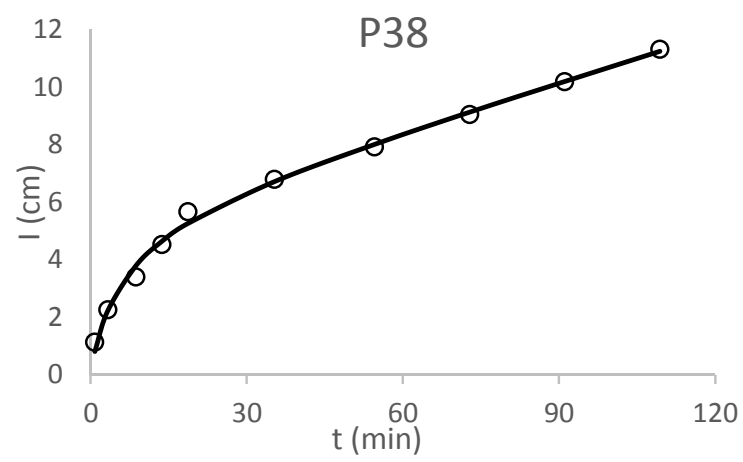

Fig. 10. Illustrative examples of the fit to infiltration data by the numerical inverse method.

Table 14. Statistics of the estimates of hydraulic parameters obtained with the numerical inverse modeling.

\begin{tabular}{lccc}
\hline Statistic & $K_{s}\left(\mathrm{~mm} \mathrm{~h}^{-1}\right)$ & $n$ & $\alpha$ \\
\hline Minimum & 0.048 & 1.083 & 0.003 \\
Maximum & 2.074 & 10.860 & 0.310 \\
Average & 0.327 & 2.139 & 0.029 \\
Standard deviation $(\sigma)$ & 0.375 & 2.958 & 0.045 \\
Coefficient of variation $(\mathrm{CV})$ & 1.145 & 1.383 & 1.552 \\
\hline
\end{tabular}

result from different factors. At first, all the methods used here rely on specific analytical approaches and specific models. Any discrepancy between the models may result in differences in estimates for given parameters, including $K_{s}$. That point was already discussed for Haverkamp's model designed to predict the cumulative infiltrations analytically (Haverkamp et al., 1994). Lassabatere et al. (2009) already showed that Haverkamp's model did not fit appropriately the nominal cumulative infiltrations (numerically generated by resolving Richards equation). Consequently, the values of estimates may compensate for the inaccuracy of the model, thus inducing a bias in estimates.

In contrary to the contrasts in means, a similar coefficient of variations was obtained regardless of the method employed for the treatment of the data, confirming the large spatial variability. The significant decrease in the saturated hydraulic conductivity estimates has an impact on the hydrological indicators. According to the SCS method, the coating fit in the "hydrological class D" (Table 15). These values are characterized by very low permeability and high capacity to generate surface runoff when compared to shallow soils constituted of expansive clays. This result contrasts with the classifications obtained from the other models (see above), due to the reduction in the magnitude order of the conductivity values. Likewise, the criterion of characteristic permeability degree of the coating was consid- ered "Very Low" in more than $69 \%$ of the cases. The HMIs were not calculated for the inverse method due to the difficulty in obtaining the parameters $K_{s I D}$ and $K_{s 3 D}$ separately.

\subsection{Synthesis and comparison of the modeling approaches}

It is clear that depending on the considered treatment (steady versus transient state, analytical versus numerical models), the estimates for $K_{s}$ vary to a large extent. Consequently, the classification of the soils regarding the hydrological indicators changes drastically. This means that, practically, any practitioner may take different decisions on the management of the studied porous pavement, depending on his way to estimate the value of $K_{s}$. As there is no means to select a priori the right procedure and the right procedure, there is a need for strategy to select the best options.

One option could be considering that the most confident procedure would be the one that provides the best fits and optimizes the criteria of goodness of fits. With this aim, we compared the mean values of the statistical indicators $\mathrm{R}^{2}, \mathrm{RD}$, CMR, and MS between models. Firstly, all models provide satisfying values for the statistical indicators (Table 16). The mean correlation coefficient values $\left(\mathrm{R}^{2}\right)$ ranged from 0.9975 to 0.9988 , being very close to the optimum value 1.0 . The Deviation Ratio (RD) showed small average deviations from the optimal value with a maximum value of $3 \%$. The modeling efficiency (ME) varied from 0.9962 to 0.9980 . All these values indicate that all the studied models satisfactorily fitted the experimental data. Slight discrepancies between models appear when these are ranked according to the statistical indicators (Table 16, Rank-R ${ }^{2}$, Rank-RD, Rank-RMC, Rank-EM) or the averages of all the indicators (Table 16, Rank-Average). Only two models reach, at least once, the first place: the $\mathrm{Wu}$ model, for the RD and CMR criteria, and the inverse method for $\mathrm{R}^{2}$ and ME. In relation to the Residual Mass Coefficient (RMC), while 
Table 15. Hydrological classification of the coating obtained with the results provided by numerical inverse modeling $(\mathrm{FF}=\mathrm{frequency})$.

\begin{tabular}{lcc|lcc}
\hline & SCS & & \multicolumn{3}{c}{ GP } \\
\hline Criteria & FF & $\%$ & Criteria & FF & \% \\
\hline Class A & 1 & 2.17 & High & 0 & 2.17 \\
Class B & 0 & 0.00 & Medium & 13 & 0.00 \\
Class C & 1 & 2.17 & Low & 32 & 28.26 \\
Class D & 44 & 95.65 & Very Low & 0 & 69.57 \\
& & & P. waterproof & 0.00 & 0 \\
\hline
\end{tabular}

Table 16. Evaluation of the adjustment quality of the methods applied to field data.

\begin{tabular}{lccccccc}
\hline Parameter & WU & PH & ST & BR & SW & KN & IN \\
\hline R $^{2}$ & 0.9975 & 0.9976 & 0.9980 & 0.9979 & 0.9983 & 0.9980 & 0.9988 \\
DR & 1.0022 & 0.9951 & 1.0177 & 1.0196 & 1.0120 & 1.0179 & 0.9703 \\
RMC & -0.0003 & -0.0019 & 0.0022 & 0.0024 & 0.0014 & 0.0022 & 0.0064 \\
ME & 0.9962 & 0.9963 & 0.9974 & 0.9972 & 0.9977 & 0.9973 & 0.9980 \\
Rank - R & 7 & 6 & 3 & 5 & 2 & 4 & 1 \\
RANK (DR) & 1 & 2 & 4 & 6 & 3 & 5 & 7 \\
RANK (RMC) & 1 & 3 & 4 & 6 & 2 & 5 & 7 \\
RANK (ME) & 7 & 6 & 3 & 5 & 2.25 & 4.5 & 1 \\
RANK (Average) & 4 & 4.25 & 3.5 & 5.5 & 2.25 & 4 \\
\hline
\end{tabular}

the Wu et al. (1999) and Philip (1957) models tended to overestimate the fitted curves, all other models evaluated tended to underestimate the hydraulic parameters. In the general analysis, the average rank of the statistical criteria pointed to the Swartzendruber (1987) model as the one that exhibited the best fits, with the best mean rank (2.25) among the evaluated methods. The Brutsaert (1977) model presented the worst performance for describing field data, with an average rank of 5.5. On the sole basis of these indicators, the Swartzendruber (1987) model should be considered. However, the sole criteria of goodness of fits should not be considered, since non-uniqueness and equifinality could affect estimation procedures (Pollacco et al., 2013) and additional data may be needed to strengthen the inverting procedures (Šimůnek et al., 1998). The estimation of saturated hydraulic conductivity in permeable pavements is of fundamental importance for understanding the processes of generating runoff and the dynamics of infiltration in natural rain conditions. In general regarding water infiltration and runoff generation, conductivity is one of the most sensitive parameters (Costa et al., 2020).

\section{CONCLUSIONS}

Several modeling approaches were investigated for the treatment of previously acquired Beerkan infiltration data and the derivation of the hydraulic conductivity of the permeable pavement coating, more precisely, the hydraulic conductivity of the volumes of soil between the concrete blocks. The onedimensional infiltration models resulted in average conductivities three times higher than the methods based on the analysis of the steady state. The adaptation of the one-dimensional models to 3D (with the addition of the term related to radial infiltration) may be one of the factors for such a difference. Indeed, the term added to pass from $1 \mathrm{D}$ to $3 \mathrm{D}$ increases the infiltration at given values of $K_{s}$ and $S$, and the values of their related estimates diminish to allow the fit to the same data with the additional term. The saturated hydraulic conductivities resulting from the inverse method differ considerably from the values previously obtained. In this case, this decrease in $K_{s}$ is probably compensated by the values of the other parameters, in particular the scale parameter $\alpha$. The high standard deviations of $K_{s}$, regardless of the studied model, demonstrate the high variability of the pavement infiltration capacity. This result was already expected, because of the daily parking lot use and the absence of maintenance actions, resulting in potentially contrasting compactions.

There is no point in choosing the correct values of $K_{s}$ on the basis of the quality of the fit. The application of the models provided accurate fits according to all the statistical criteria used in this study. It did not present significant differences in the capacity to describe the experimental data from empirical and numerical models. The ranking of the statistical criteria to evaluate the goodness of fits points to the Swartzendruber (1987) model as the best one. Conversely, the Brutsaert (1977) model presented the worst performances. However, the related fits remained good in all cases. Besides, it must be borne in mind that the goodness of fits may not be the sole parameters for the selections of estimates (Pollacco et al., 2013). Indeed, the plausibility and the physical soundness of the values of estimated parameters must be ensured. But, unfortunately, the analysis of the values and their plausibility again does not help select the right values since all methods provided plausible values.

The contrasting set of values for the saturated hydraulic conductivity leads to different conclusions regarding the PP infiltration capacity. For height of the nine infiltration methods used to estimate $K_{s}$, the hydrological classification of the permeable pavement by the SCS methodology indicates "Group A." Such class is associated to low generation of surface flow and high infiltration capacity. In contrast, the average hydraulic conductivity calculated by the inverse method classified the coating as "Group D," i.e., potential for runoff generation. In terms of degree of permeability, "Average GP" was obtained for $88 \%$ of the studied cases with all the models, except for the inverse method for which "Very Low GP" was obtained. The analysis of the individual results also allowed the identification of isolated points with very low permeability, due to the partial and/or total clogging of the coating.

Although both classification criteria use saturated hydraulic conductivity for the determination of the permeable surface behavior, the established values ranges differ widely, whereas orders of magnitude for $K_{s}$ are more rigorous in the evaluation 
by the criterion of permeability degree. This study shows that the method used to estimate saturated hydraulic conductivity may lead to contrasting values and thus contrasting conclusions with regards to the hydrological properties. Therefore, the elaboration of the maintenance plan is advised on the basis of the monitoring of the saturated hydraulic conductivity, taking into account the potential variability on conclusions, depending on the methods considered for the estimations of this parameter.

\section{REFERENCES}

AlShareedah, O., Nassiri, S., 2021. Pervious concrete mixture optimization, physical, and mechanical properties and pavement design: A review. Journal of Cleaner Production 288, 125095. https://doi.org/10.1016/j.jclepro.2020.125095

Angulo-Jaramillo, R., Bagarello, V., Iovino, M., Lassabatere, L., 2016. Infiltration measurements for soil hydraulic characterization, Infiltration Measurements for Soil Hydraulic Characterization. Springer, Switzerland. https://doi.org/10. 1007/978-3-319-31788-5

Antonino, A.C.D., Soares, W. de A., Silva, E. da, Lima, J. de S., Netto, A.M., LIMA, C., 2004. Utilização do método inverso para a caracterização hidrodinâmica de um neossolo flúvico. Revista Brasileira de Recursos Hídricos, 9, 81-87.

Bagarello, V., Di Prima, S., Iovino, M., 2017. Estimating saturated soil hydraulic conductivity by the near steady-state phase of a Beerkan infiltration test. Geoderma, 303, 70-77. https://doi.org/10.1016/j.geoderma.2017.04.030

Bagarello, V., Di Prima, S., Iovino, M., 2014a. Comparing alternative algorithms to analyze the Beerkan infiltration experiment. Soil Science Society of America Journal, 78, 724736.

Bagarello, V., Di Prima, S., Iovino, M., Provenzano, G., 2014 b. Estimating field-saturated soil hydraulic conductivity by a simplified Beerkan infiltration experiment. Hydrological Processes, 28, 1095-1103. https://doi.org/10.1002/hyp.9649

Baloch, M.A., Ames, D.P., Tanik, A., 2015. Hydrologic impacts of climate and land-use change on Namnam Stream in Koycegiz Watershed, Turkey. Int. J. Environ. Sci. Technol., 12, 1481-1494. https://doi.org/10.1007/s13762-014-0527-x

Boogaard, F., Lucke, T., Beecham, S., 2014. Effect of age of permeable pavements on their infiltration function. CLEAN - Soil, Air, Water, 42, 146-152. https://doi.org/10. 1002/clen.201300113

Braud, I., De Condappa, D., Soria, J.M., Haverkamp, R., Angulo-Jaramillo, R., Galle, S., Vauclin, M., 2005. Use of scaled forms of the infiltration equation for the estimation of unsaturated soil hydraulic properties (the Beerkan method). European Journal of Soil Science, 56, 361-374.

Brunetti, G., Šimŭnek, J., Piro, P., 2016. A comprehensive numerical analysis of the hydraulic behavior of a permeable pavement. Journal of Hydrology, 540, 1146-1161.

Brutsaert, W., 1977. Vertical infiltration in dry soil. Water Resources Research, 13, 363-368. https://doi.org/10. 1029/WR013i002p00363

Canholi, A., 2015. Drenagem urbana e controle de enchentes. Oficina de textos.

Chandrappa, A.K., Biligiri, K.P., 2016. Pervious concrete as a sustainable pavement material-Research findings and future prospects: A state-of-the-art review. Construction and Building Materials, 111, 262-274.

Costa, I.R. de A., Coutinho, A.P., Montenegro, S.M.G.L., Rabelo, A.E.C. de G. da C., Santos Neto, S.M. dos, Alves, E.M., Antonino, A.C.D., 2020. Sensitivity of hydrodynamic parameters in the simulation of water transfer processes in a permeable pavement. RBRH, 25, e47. https://doi.org/10. 1590/2318-0331.252020190188

Coutinho, A.P., Lassabatere, L., Montenegro, S., Antonino, A.C.D., Angulo-Jaramillo, R., Cabral, J.J.S.P., 2016. Hydraulic characterization and hydrological behaviour of a pilot permeable pavement in an urban centre, Brazil. Hydrol. Process., 30, 4242-4254. https://doi.org/10.1002/hyp.10985

Fletcher, T.D., Andrieu, H., Hamel, P., 2013. Understanding, management and modelling of urban hydrology and its consequences for receiving waters: A state of the art. Advances in Water Resources, 51, 261-279.

Fletcher, T.D., Shuster, W., Hunt, W.F., Ashley, R., Butler, D., Arthur, S., Trowsdale, S., Barraud, S., Semadeni-Davies, A., Bertrand-Krajewski, J.-L., others, 2015. SUDS, LID, BMPs, WSUD and more-The evolution and application of terminology surrounding urban drainage. Urban Water Journal, $12,525-542$.

Haverkamp, R., Ross, P.J., Smettem, K.R.J., Parlange, J.Y., 1994. 3-Dimensional analysis of infiltration from the disc infiltrometer .2. Physically-based infiltration equation. Water Resources Research, 30, 2931-2935.

Huang, J., He, J., Valeo, C., Chu, A., 2016. Temporal evolution modeling of hydraulic and water quality performance of permeable pavements. Journal of Hydrology, 533, 15-27.

Kodešová, R., Kodeš, V., Žigová, A., Šimŭnek, J., 2006. Impact of plant roots and soil organisms on soil micromorphology and hydraulic properties. Biologia, 61, S339-S343.

Lambe, T.W., Whitman, R.V., 1991. Soil Mechanics. John Wiley \& Sons.

Lassabatere, L., Angulo-Jaramillo, R., Goutaland, D., Letellier, L., Gaudet, J.P., Winiarski, T., Delolme, C., 2010. Effect of the settlement of sediments on water infiltration in two urban infiltration basins. Geoderma, 156, 316-325. http://dx.doi. org/10.1016/j.geoderma.2010.02.031

Lassabatere, L., Angulo-Jaramillo, R., Soria Ugalde, J.M., Cuenca, R., Braud, I., Haverkamp, R., 2006. Beerkan estimation of soil transfer parameters through infiltration experiments-BEST. Soil Science Society of America Journal, 70, 521-532.

Lassabatere, L., Angulo-Jaramillo, R., Soria-Ugalde, J.M., Simunek, J., Haverkamp, R., 2009. Numerical evaluation of a set of analytical infiltration equations. Water Resources Research, 45, W12415. https://doi.org/doi:10.1029/2009 WR007941

Lassabatere, L., Angulo-Jaramillo, R., Winiarski, T., Yilmaz, D., 2013. BEST method: Characterization of soil unsaturated hydraulic properties. In: Proceedings of the 1st PanAmerican Conference on Unsaturated Soils, PanAmUNSAT 2013. CRC Press, pp. 527-532.

Lassabatere, L., Yilmaz, D., Peyrard, X., Peyneau, P.E., Lenoir, T., Šimůnek, J., Angulo-Jaramillo, R., 2014. New analytical model for cumulative infiltration into dual-permeability soils. Vadose Zone Journal, 13, 1-15. https://doi.org/10. 2136/vzj2013.10.0181

Marinho, M.N., Coutinho, A.P., Santos Neto, S.M. dos, Casagrande, C.A., Santos, G.T.L., Carneiro, A.M.P., 2020. Mathematical modeling of the infiltration in a permeable pavement on the field scale. RBRH, 25, e39. https://doi.org/10.1590/2318-0331.252020200052

Mualem, Y., 1976. A new model for predicting the hydraulic conductivity of unsaturated porous media. Water Resources Research, 12, 513-522.

Mullaney, J., Lucke, T., 2014. Practical review of pervious pavement designs. CLEAN - Soil, Air, Water, 42, 111-124. https://doi.org/10.1002/clen.201300118 
Philip, J., 1957. The theory of infiltration: 1. The infiltration equation and its solution. Soil Science, 83, 345-358.

Philip, J.R. a, Knight, J.H. b, 1974. On solving the unsaturated flow equation: 3 . new quasi-analytical technique. Soil Science, 117, 1-13.

Pollacco, J.A.P., Nasta, P., Soria-Ugalde, J.M., AnguloJaramillo, R., Lassabatere, L., Mohanty, B.P., Romano, N., 2013. Reduction of feasible parameter space of the inverted soil hydraulic parameter sets for Kosugi model. Soil Sci., 178. 267-280. https://doi.org/10.1097/SS.0b013e3182a2da21

Rawls, W., Gish, T., Brakensiek, D., 1991. Estimating soil water retention from soil physical properties and characteristics. In: Advances in Soil Science. Springer, pp. 213-234.

Rawls, W.J., Ahuja, L.R., Brakensiek, D.L., Shirmohammadi, A., 1992. Infiltration and soil water movement. In: Handbook of Hydrology. McGraw-Hill Inc., New York, pp. 5.15.51 .

Reynolds, W., Elrick, D., 1990. Ponded infiltration from a single ring: I. Analysis of steady flow. Soil Science Society of America Journal, 54, 1233-1241.

Šimůnek, J., Angulo-Jaramillo, R., Schaap, M.G., Vandervaere, J.-P., van Genuchten, M.T., 1998. Using an inverse method to estimate the hydraulic properties of crusted soils from tension-disc infiltrometer data. Geoderma, 86, 61-81.

Šimůnek, J., van Genuchten, M.T., 1997. Estimating unsaturated soil hydraulic properties from multiple tension disc infiltrometer data. Soil Science, 162, 383-398.

Šimůnek, J., van Genuchten, M.T., Sejna, M., 2008. Development and applications of the HYDRUS and STANMOD software packages and related codes. Vadose Zone Journal, 7, 587-600.

Smettem, K., Kirkby, C., Chittleborough, D., 1994. Hydrologic response of undisturbed soil cores to simulated rainfall. Soil Res., 32, 1175-1187.

Stroosnijder, L., 1976. Infiltratie en herverdeling van water in grond. Pudoc.

Swartzendruber, D., 1987. A quasi-solution of Richards' equation for the downward infiltration of water into soil. Water Resources Research, 23, 809-817.

Terzaghi, K., Peck, R.B., Mesri, G., 1996. Soil mechanics in engineering practice. John Wiley \& Sons.
Turco, M., Kodešová, R., Brunetti, G., Nikodem, A., Fér, M., Piro, P., 2017. Unsaturated hydraulic behaviour of a permeable pavement: Laboratory investigation and numerical analysis by using the HYDRUS-2D model. Journal of Hydrology, 554, 780-791.

van Genuchten, M.T., 1980. A closed-form equation for predicting the hydraulic conductivity of unsaturated soils. Soil Science Society of America Journal, 44, 892-898.

White, I., Sully, M., 1987. Macroscopic and microscopic capillary length and time scales from field infiltration. Water Resources Research, 23, 1514-1522.

Wu, L., Pan, L., Mitchell, J., Sanden, B., 1999. Measuring saturated hydraulic conductivity using a generalized solution for single-ring infiltrometers. Soil Science Society of America Journal, 63, 788-792.

Xie, N., Akin, M., Shi, X., 2019. Permeable concrete pavements: A review of environmental benefits and durability. Journal of Cleaner Production, 210, 1605-1621.

Xu, X., Lewis, C., Liu, W., Albertson, J., Kiely, G., 2012. Analysis of single-ring infiltrometer data for soil hydraulic properties estimation: Comparison of BEST and $\mathrm{Wu}$ methods. Agricultural Water Management, 107, 34-41.

Yilmaz, D., Lassabatere, L., Angulo-Jaramillo, R., Deneele, D., Legret, M., 2010. Hydrodynamic characterization of basic oxygen furnace slag through an adapted BEST method. Vadose Zone Journal, 9, 107-116. https://doi.org/10.2136/ vzj2009.0039

Yilmaz, D., Lassabatere, L., Deneele, D., Angulo-Jaramillo, R., Legret, M., 2013. Influence of carbonation on the microstructure and hydraulic properties of a basic oxygen furnace slag. Vadose Zone Journal, 12. https://doi.org/10.2136/ vzj2012.0121

Zhu, H., Yu, M., Zhu, J., Lu, H., Cao, R., Zhang, L., 2019. Simulation study on effect of permeable pavement on reducing flood risk of urban runoff. International Journal of Transportation Science and Technology, 8, 4, 373-382.

Received 3 April 2021

Accepted 30 June 2021 